\title{
Pathogen Recognition by the Long Pentraxin PTX3
}

\author{
Federica Moalli, ${ }^{1}$ Sebastien Jaillon, ${ }^{1}$ Antonio Inforzato, ${ }^{1}$ Marina Sironi, ${ }^{1}$ \\ Barbara Bottazzi, ${ }^{1}$ Alberto Mantovani, ${ }^{1,2}$ and Cecilia Garlanda ${ }^{1}$ \\ ${ }^{1}$ Department of Immunology and Inflammation, Istituto Clinico Humanitas IRCCS, Via Manzoni 113, 20089 Rozzano, Italy \\ ${ }^{2}$ Department of Translational Medicine, University of Milan, 20089 Rozzano, Italy
}

Correspondence should be addressed to Cecilia Garlanda, cecilia.garlanda@humanitasresearch.it

Received 16 December 2010; Accepted 21 March 2011

Academic Editor: Jie-Oh Lee

Copyright () 2011 Federica Moalli et al. This is an open access article distributed under the Creative Commons Attribution License, which permits unrestricted use, distribution, and reproduction in any medium, provided the original work is properly cited.

\begin{abstract}
Innate immunity represents the first line of defence against pathogens and plays key roles in activation and orientation of the adaptive immune response. The innate immune system comprises both a cellular and a humoral arm. Components of the humoral arm include soluble pattern recognition molecules (PRMs) that recognise pathogen-associated molecular patterns (PAMPs) and initiate the immune response in coordination with the cellular arm, therefore acting as functional ancestors of antibodies. The long pentraxin PTX3 is a prototypic soluble PRM that is produced at sites of infection and inflammation by both somatic and immune cells. Gene targeting of this evolutionarily conserved protein has revealed a nonredundant role in resistance to selected pathogens. Moreover, PTX3 exerts important functions at the cross-road between innate immunity, inflammation, and female fertility. Here, we review the studies on PTX3, with emphasis on pathogen recognition and cross-talk with other components of the innate immune system.
\end{abstract}

\section{Introduction}

The innate immune system is evolutionarily older than the adaptive immune system and constitutes the first line of defence against pathogens. Innate immunity plays key roles in activation and orientation of adaptive immunity that provides the immunological memory. Components of the innate immune system that are involved in pathogen recognition and initiation of the immune response are germlineencoded receptors known as pattern recognition molecules (PRMs). These receptors recognize microbes or microbial moieties collectively named pathogen-associated molecular patterns (PAMPs) [1]. Based on cellular localisation and function, PRMs are classified into two major groups: (i) cell-associated receptors, which are localised in different cellular compartments and include endocytic receptors, such as scavenger receptors [2], signalling receptors, such as toll-like receptors (TLR) [3], and nucleotide-binding oligomerization domain- (NOD-) like receptors (NLR) [4], and (ii) fluid-phase molecules or opsonins, which represent the functional ancestors of antibodies and are involved in pathogen opsonisation, complement activation, and self versus modified self-discrimination [5].

Fluid phase PRMs are essential effectors and modulators of the innate resistance in animals and humans, and form a heterogeneous group of molecules, including collectins, ficolins, and pentraxins $[6,7]$. Some soluble PRMs are stored in granules of neutrophils and rapidly released (i.e., within minutes) into the extracellular milieu upon neutrophil stimulation, others are de novo synthesised as early gene products in mononuclear phagocytes and dendritic cells (DCs); in both cases, these PRMs are locally produced at sites of immune insult. As opposed to this, certain epithelial tissues (i.e., liver) act as a remote and delayed source of systemic PRMs [5]. Despite their heterogeneity in terms of molecular structure and site/time of production, soluble PRMs share basic, evolutionarily conserved functions, including opsonisation, complement activation, agglutination, and self versus modified self-discrimination [5].

Pentraxins are pivotal components of the innate immune system. Conserved in evolution from arachnids to humans, 
they are acute-phase reactants with a characteristic multimeric structure. Based on the primary structure of the composing protomers, pentraxins are divided into two groups: short and long pentraxins [8]. C-reactive protein (CRP) and serum amyloid $\mathrm{P}$ component (SAP) are prototypic short pentraxins, whereas pentraxin 3 (PTX3) and other subsequently identified proteins represent the long pentraxin arm of the family [9].

Here, we review-past and present literature on this family of proteins with main focus on the long pentraxin 3 and its involvement in innate resistance to pathogens.

\section{The Pentraxin Superfamily}

Pentraxins are distinctively characterized by the presence in their carboxy-terminal region of a $\sim 200$ amino acid domain containing a highly conserved motif of primary sequence known as pentraxin signature $(\mathrm{HxCxS} / \mathrm{TW} \mathrm{xS}$, where $\mathrm{x}$ is any amino acid). In the 1930 s, C-reactive protein (CRP) was the first purified PRM, which was named after its ability to bind in a calcium-dependent fashion the C-polysaccharide of Streptococcus pneumoniae [10, 11]. Human SAP was subsequently identified as a closely related protein (i.e., with $51 \%$ sequence identity to human CRP) [12]. Orthologous proteins to human CRP and SAP have also been described in the hemolymph of the arthropod Limulus polyphemus, where they are involved in recognition and killing of pathogens [13-15]. Both short pentraxins are $25-\mathrm{kDa}$ proteins with a common structural organization that comprises five or ten identical subunits arranged in a pentameric radial symmetry $[12,16]$. CRP and SAP are the main acute-phase reactants in human and mouse, respectively. CRP is barely detectable in the plasma of healthy human adults $(\leq 3 \mathrm{mg} / \mathrm{L})$, but its concentration increases by as much as 1000 -fold in several pathological conditions, with a sharp rise within 6 hours of induction and a maximum at approximately 48 hours. As opposed to this, the concentration of human (but not murine) SAP is substantially invariant $(30-50 \mathrm{mg} / \mathrm{L})$, even during the early acute-phase response [17]. Human CRP and SAP are both produced by hepatocytes, where the proinflammatory cytokine IL-6 is a major inducer of CRP both on its own and in synergy with IL-1 [18].

PTX3 is the prototypic long pentraxin that was first identified in the early 1990s as a cytokine-inducible gene in endothelial cells and fibroblasts. Long pentraxins have an unrelated amino-terminal region coupled to a carboxyterminal pentraxin-like domain and differ from short pentraxins in gene organization, chromosomal localization, and cellular source, inducing stimuli and recognized ligands. Other members of the long pentraxin subfamily have been identified, including guinea pig apexin [19], neuronal pentraxin 1 (NPTX1 or NP1) [20], neuronal pentraxin 2 (NPTX2, also called Narp or NP2) [21], and the transmembrane protein neuronal pentraxin receptor (NPTXR) [22]. In an attempt to find new pentraxin domain-containing proteins, we have recently identified a new long pentraxin, which we named PTX4. Like other members of this family, the gene encoding PTX4 is well conserved from mammals to lower vertebrates. However, PTX4 has a unique pattern of mRNA expression, which is distinct from that of other long pentraxins [23].

\section{The Short Pentraxins in Innate Immunity}

Short pentraxins are important players in humoral innate immunity, where they have been described to recognise a number of diverse ligands, mostly in a calcium-dependent manner. As mentioned above, the first reported ligand of CRP is the C-polysaccharide of Streptococcus pneumoniae. This interaction is mediated by phosphorylcholine (PC), a major constituent of the C-type capsule polysaccharides [10, 11]. CRP recognizes additional pathogens, including fungi, yeasts, and bacteria, thus promoting phagocytosis and resistance to infection [24]. According to this, CRP transgenic mice are resistant to infection with Streptococcus pneumoniae, displaying longer survival time and lower mortality rate than normal littermates [25]. SAP is a calcium-dependent lectin originally purified based on its binding to the agarose component 4,6-cyclin pyruvate acetal of $\beta$-D-galactose [26]. Like CRP, SAP binds a number of bacteria, such as Streptococcus pyogenes and Neisseria meningitidis [27, 28]. Binding of SAP to influenza virus [29] and lipopolysaccharide (LPS) has also been reported $[28,30]$. In this regard, SAP has been described to prevent LPS-mediated complement activation and LPS toxicity $[28,31]$. It has been proposed that both short pentraxins, either in aggregated form or in complex with ligands, interact with the globular head modules of the complement component $\mathrm{C} 1 \mathrm{q}$ [32]. However, the relationship between ligand binding and function of these proteins is still a matter of debate [33]. Interestingly, CRP has been shown to protect mice from infection with Salmonella typhimurium, a pathogen that is not recognized by this short pentraxin, thus indicating that in some cases CRP binding to pathogens is not necessary to mediate host protection [34]. Similar observations have been reported for SAP, which exhibits a host defence function against pathogens that it does not bind. In contrast, the interaction with SAP can enable bacteria to evade neutrophil phagocytosis and display enhanced virulence, therefore indicating a dual role of SAP in bacterial infections [28]. Furthermore, CRP-mediated activation of the classical complement pathway has no role in protecting mice against $S$. pneumoniae infection [35].

The short pentraxins participate in activation and regulation of the three complement pathways (i.e., classical, lectin, and alternative) (reviewed in $[5,8]$ ), by interacting with C1q (CRP and SAP) [32], ficolins (CRP) [36, 37], and factor $\mathrm{H}$ (CRP) [38-40]. It has been suggested that complement activation by short pentraxins might favour removal of the apoptotic debris, with potential implications in preventing the onset of autoimmune diseases [41]. Specific and saturable binding to all three classes of Fc $y$ receptors (Fc $\gamma$ Rs) has been demonstrated for both CRP and SAP, where these interactions mediate phagocytosis of apoptotic cells and microorganisms [42-44]. In a recent study, a 3D structure of human SAP in complex with the extracellular domain of Fc $\gamma$ RIIa has been generated based on X-ray 
crystallography that suggests short pentraxins and $\operatorname{IgG}$ to share the same binding site on Fc $\gamma$ Rs [45]. Consistent with these observations, CRP and SAP proved effective to inhibit immune-complex-mediated phagocytosis [45]. Therefore, pentraxins can activate both complement and $\mathrm{Fc} \gamma \mathrm{Rs}$ pathways, which resembles the functional properties of antibodies.

\section{The Long Pentraxin PTX3}

4.1. Gene Organization and Expression. The human PTX3 gene has been localized on chromosome 3 band q25 and is organized in three exons separated by two introns. The first two exons code for the leader peptide and the $\mathrm{N}$ terminal domain of the protein, respectively, and the third exon encodes the pentraxin domain [46]. The murine gene presents the same structural organization and is located on chromosome 3 [47]. The proximal promoters of both human and murine PTX3 genes share numerous potential enhancerbinding elements, including Pu1, AP-1, NF- $\kappa \mathrm{B}, \mathrm{SP} 1$, and NF-IL-6 sites $[47,48]$. It has been shown that the NF- $\kappa$ B binding site is essential for the transcriptional response to proinflammatory cytokines (i.e., TNF- $\alpha$ and IL-1 $\beta$ ), whereas AP-1 controls the basal transcription of PTX3 $[47,48]$.

As stated above, PTX3 was originally identified as a cytokine-inducible gene in vascular endothelial cells and fibroblasts $[46,49]$. PTX3 expression is rapidly induced in a variety of additional cell types by several stimuli, such as cytokines (e.g., IL-1 $\beta$, TNF- $\alpha$ ), TLR agonists, microbial moieties (e.g., LPS, OmpA, lipoarabinomannans), or intact microorganisms [17]. Myeloid dendritic cells are a major source of PTX3 that is also expressed by monocytes, macrophages, smooth muscle cells, kidney epithelial cells, synovial cells, chondrocytes, adipocytes, and alveolar epithelial cells and glial cells as well as fibroblasts and endothelial cells [46, 50-57]. In contrast to these cell types which express PTX3 upon stimulation, both human and murine lymphatic endothelial cells constitutively express the protein [58-60].

Resting T and B lymphocytes and natural killer cells do not express PTX3 mRNA [61]. PTX3 is constitutively stored in the specific granules of neutrophils (i.e., with $24.9 \pm 3.8 \mathrm{ng}$ of protein per $10^{6}$ cells) and is released in response to TLR engagement by micro-organisms or TLR agonists [62, 63]. Expression of the PTX3 mRNA is temporally confined to immature myeloid cells. PTX3 can partially localize in neutrophil extracellular traps (NETs) formed by extruded DNA and neutrophil-associated-PTX3 promotes the in vivo control of Aspergillus fumigatus infection [62]. Moreover, PTX3 has been found in neutrophils in biopsies of colon mucosa from patients with inflammatory bowel disease and in neutrophils infiltrating the atherosclerotic plaque $[63,64]$.

The inflammatory cytokine IL-1 $\beta$ induces high amounts of PTX3 in peripheral blood mononuclear cells, while IL-6 (i.e., the main inducer of CRP and SAP) as well as typical activators of monocytes, such as monocyte chemotactic protein 1 (MCP-1/CCL2), macrophage colony stimulating factor (M-CSF), granulocyte-macrophage colony stimulating factor (GM-CSF), and interferon- $\gamma$ (IFN- $\gamma)$, are inactive
[61]. However, PTX3 expression has been documented in Castleman's disease (i.e., which is propelled by IL-6) and in Kaposi's sarcoma cells stimulated with viral IL- 6 encoded by human herpesvirus-8 $[65,66]$. IFN- $\gamma$ and IL-10 have different effects on PTX3 expression. While IFN- $\gamma$ inhibits PTX3 production in dendritic cells, monocytes, and macrophages both at a transcriptional level and reducing transcript stability, IL-10 amplifies LPS-induced PTX3 expression [63, 67]. IL-4, dexamethasone, $1 \alpha, 25$-dihydroxivitamin D3, and prostaglandin E2 also inhibit LPS-induced PTX3 in myeloid dendritic cells [67].

Different signalling pathways can affect PTX3 production, depending on cell type and/or stimuli. PTX3 expression in a model of acute myocardial ischemia is controlled by the NF- $\kappa$ B pathway [68], while induction of the protein by TNF- $\alpha$ in lung epithelial cells does not require NF- $\kappa$ B, but rather involves the c-Jun $\mathrm{N}$-terminal Kinase (JNK) pathway [54]. Moreover, production of PTX3 in endothelial cells that is induced by high-density lipoproteins (HDLs) requires the activation of the PI3K/Akt pathway through G-coupled lysosphingolipid receptors [69].

Expression of PTX3 is modulated by glucocorticoid hormones (GCs) in a cell-dependent manner. GCs alone have been shown to induce or, under inflammatory conditions, enhance and extend PTX3 production in nonhematopoietic cells (e.g., fibroblasts and endothelial cells). In contrast, GCs treatment inhibits PTX3 production in hematopoietic cells (e.g., dendritic cells and macrophages) [70]. In keeping with these observations, in vivo administration of GCs increases the blood levels of PTX3. Moreover, patients with Cushing's syndrome exhibit increased levels of circulating PTX3, and reduced titers of the protein have been found in subjects affected by iatrogenic hypocortisolism [70]. The divergent effects observed in hematopoietic and nonhematopoietic cells are likely due to the different mechanisms of action of the glucocorticoid receptor in the two cell types. In nonhematopoietic cells, GC receptor acts as a liganddependent transcription factor (i.e., through a dimerizationdependent mechanism) to induce PTX3 expression, whereas in hematopoietic cells the GC receptor represses the protein expression by interfering with the action of other signalling pathways, probably NF- $\kappa \mathrm{B}$ and AP-1 (i.e., through a dimerization-independent way) [70].

4.2. Protein Structure. Human PTX3 is a multimeric glycoprotein, whose composing subunits are made of 381 amino acids, including a 17-residue signal peptide [46]. PTX3 primary sequence is highly conserved among animal species. Like other members of the long-pentraxin family, PTX3 is composed of a unique $\mathrm{N}$-terminal region coupled to a 203 amino acid C-terminal domain homologous to the short pentraxins CRP and SAP (Figure 1(a)) [71]. The N-terminal region (residues 18-178 of the preprotein) is unrelated to any known protein structure. Nevertheless, secondary structure predictions indicate that this part of the protein is likely to form four $\alpha$-helices, three of which (amino acids 78$97,109-135$, and 144-170) are probably involved in the formation of coiled-coil structures [72]. As stated above, 


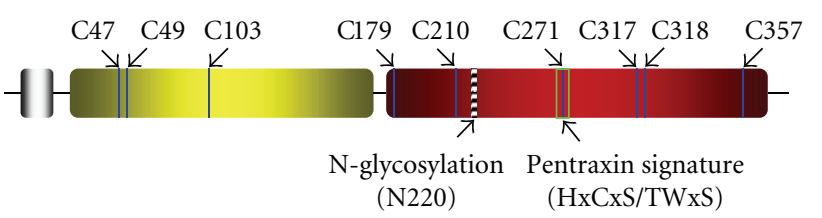

(a)

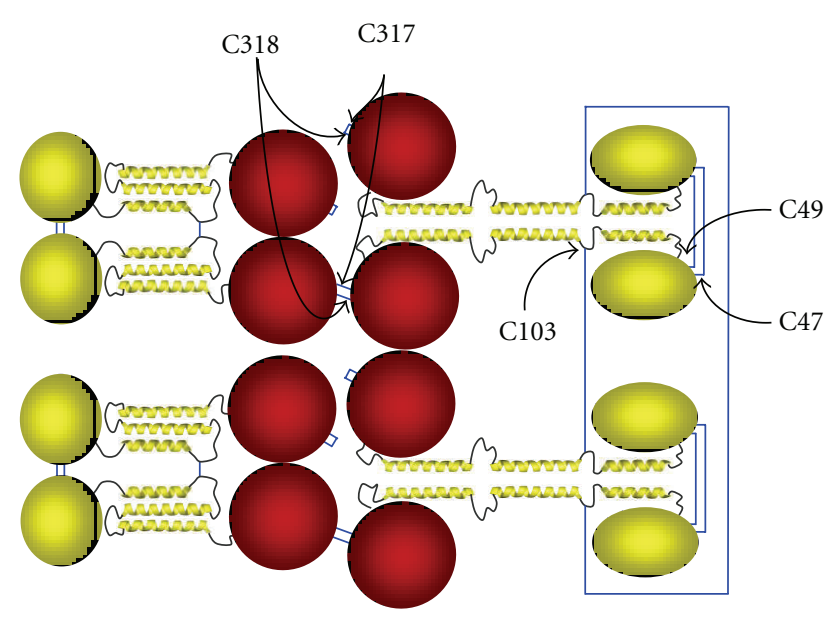

(b)
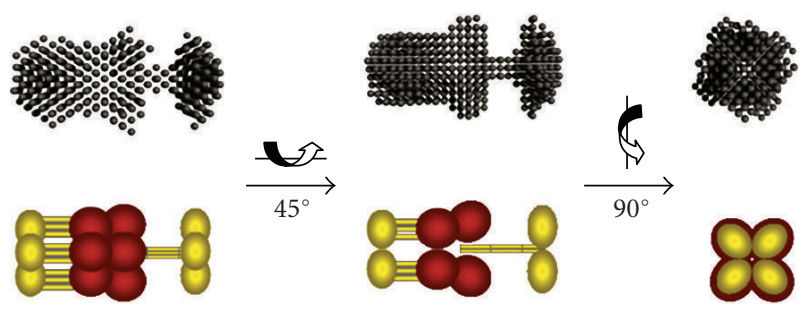

(c)

FIgURE 1: Model of the PTX3 octamer: arrangement of protomer subunits. (a) Schematic representation of the PTX3 protomer showing the $\mathrm{N}$-terminal domain in yellow, followed by the globular pentraxin domain in red. Positions of the Cys residues, the $\mathrm{N}$ glycosylation site at Asn220, and the pentraxin signature motif are indicated (see text for details). (b) Disulfide bond organization of the PTX3 octamer. The N-terminal domain (yellow) is comprised of an $\mathrm{N}$-terminal segment followed by three $\alpha$-helices (see text). The $\alpha$-helical regions of the $\mathrm{N}$-terminal domains, predicted to form coiled-coil-like structures, are hypothesized to adopt two distinct structural arrangements: either an extended conformation (right) in which four protomers associate through interchain interactions (i.e., to form tetramers) or a compact organization (left) where each protomer self-associates to form an antiparallel three-helix bundle (i.e., to form dimer of dimers). Cys 317 and Cys318 in the C-terminal pentraxin domains (denoted in red) link the protomers (i.e., a tetramer and two dimers) into octamers. (c) A comparison of the SAXS envelope with a schematic model for PTX3-based on the two different organizations proposed for the N-terminal domain above; the $\alpha$-helical segments of the $\mathrm{N}$-terminal domain are depicted as yellow rods. The C-terminal pentraxin domains are in red. the C-terminal domain of PTX3 (residues 179-381 of the preprotein) is homologous to the short-pentraxins CRP and SAP, with up to $57 \%$ similarity $[71,73]$. Therefore, threedimensional models of this domain have been generated that are based on the crystallographic structures of CRP and SAP and show the pentraxin domain of PTX3 to adopt a $\beta$-jelly roll topology, similar to that found in legume lectins $[55,74,75]$. Interestingly, the amino acids residues that form the calcium-binding pocket in CRP and SAP are missing in the pentraxin domain of PTX3, which might explain some binding properties of this long pentraxin (e.g., PTX3 binds C1q in a calcium-independent manner) [75]. Studies performed with recombinant preparations of the $\mathrm{N}$ - and C-terminal domains of PTX3 have indicated that among PTX3 ligands, FGF2, inter- $\alpha$-inhibitor, and conidia of A. fumigatus each bind to the $\mathrm{N}$-terminal region [76-78]; $\mathrm{C} 1 \mathrm{q}$ and P-selectin interact with the pentraxin-like domain $[71,79,80]$, whereas both domains have been implicated in the interaction with complement factor $\mathrm{H}$ [81] (see below).

A single $\mathrm{N}$-glycosylation site has been identified in the C-terminal domain of PTX3 at Asn220 [74] (Figure 1(a)). This site is fully occupied by complex-type oligosaccharides, mainly fucosylated and sialylated biantennary sugars with a minor fraction of tri- and tetra-antennary glycans. Most importantly, PTX3 glycosylation has been shown to affect the protein binding to a number of ligands, thus suggesting that changes in the glycosylation status might represent a strategy to tune the biological activity of this long pentraxin (see below).

In addition to the multidomain organization, the human PTX3 protein shows a complex quaternary structure with protomer subunits assembled into high order oligomers stabilized by disulfide bonds [71]. Mass spectrometry and site directed mutagenesis analyses of the recombinant human protein indicate that PTX3 is made of covalent octamers (i.e., with a molecules mass of $340 \mathrm{kDa}$ ), where cysteine residues at positions 47,49 , and 103 in the $\mathrm{N}$-terminal region form three interchain disulfides holding four protein subunits in a tetrameric arrangement. Two tetramers are linked together to form an octamer by additional interchain bridges involving the C-terminal domain cysteines Cys 317 and Cys318 [82] (Figure 1(b)). A low-resolution model of the intact PTX3 molecule has been generated based on data from Electron Microscopy (EM) and Small Angle X-ray Scattering (SAXS), that shows the eight subunits of the protein fold into an elongated structure with a large and a small domain interconnected by a stalk region [83] (Figure 1(c)). This oligomerization state and the asymmetric shape of the molecule make PTX3 unique amongst pentraxins. The only other pentraxin that forms an octamer is SAP from Limulus polyphemus, which, however, has been reported to fold into a doubly stacked octameric ring [13].

As anticipated above, the structural determinants of the PTX3 quaternary organization are mainly localised in the N-terminal domain, where this region mediates the association of protomers into tetramers via both covalent (i.e., disulfide bonds) and noncovalent (i.e., interchain coiled coils) interactions [83] (Figure 1(b)). Besides their structural role as building blocks of the PTX3 molecule, the N-terminal 


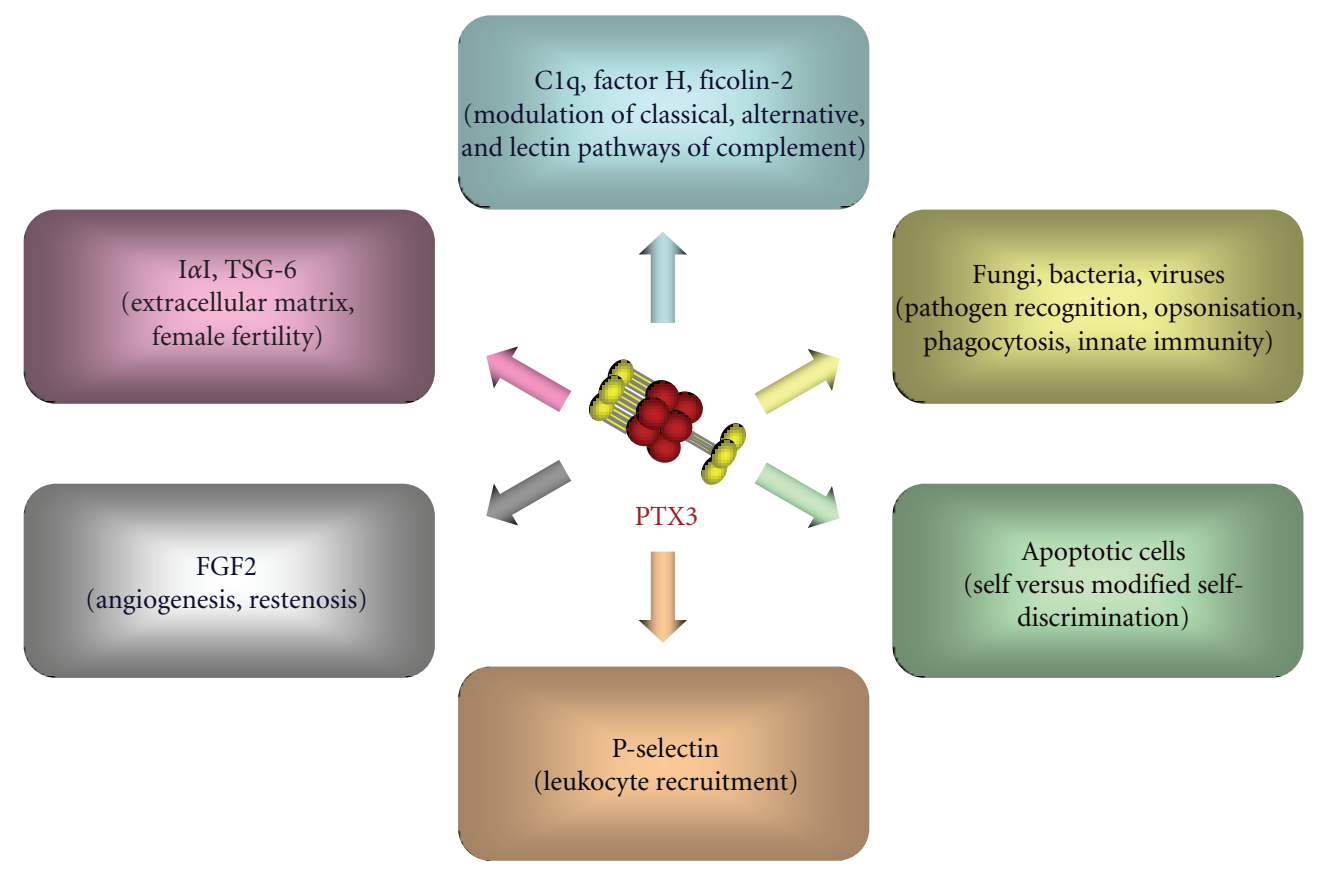

FIGURE 2: Schematic representation of the most relevant PTX3 ligands, classified based on the functional implications of their interaction with the long pentraxin.

domain tetramers act as functional units in the recognition of inter- $\alpha$-inhibitor $(\mathrm{I} \alpha \mathrm{I})$ and Fibroblast Growth Factor 2 (FGF2), two main ligands of PTX3 in cumulus oophorus expansion and angiogenesis, respectively [76, 77]. Therefore, the PTX3 quaternary structure plays a key role in dictating the protein binding properties and, ultimately, its biological functions. The structural complexity and modular nature of the PTX3 protein, as described above, probably provide a molecular basis to explain the rather broad spectrum of cellular and molecular targets that are recognized by this long pentraxin and the diversity of its biological roles (Figure 2). Here, we have classified the most relevant ligands of PTX3 based on the functional implications of their interaction with this protein, with major emphasis on complement regulation and pathogen recognition.

4.3. Interaction with Complement. The first described and best characterized ligand of PTX 3 is the complement component C1q $[71,79]$. PTX3 binds to plastic immobilized $\mathrm{C} 1 \mathrm{q}$, likely interacting with charged residues localized in the apex of the $\mathrm{Clq}$ globular heads (gC1q) $[32,79]$. In the same experimental conditions, PTX3 fails to interact with other components of the complement system, such as C3 and C4 (B. Bottazzi and L. Deban, unpublished observations). Interaction of $\mathrm{C} 1 \mathrm{q}$ with plastic-immobilized PTX3, an experimental condition that could mimic the surface of microbes, results in the activation of the classical complement cascade, measured as $\mathrm{C} 3$ and $\mathrm{C} 4$ deposition. On the other hand, the presence of PTX3 in solution resulted in a dose-dependent inhibition of C1q hemolytic activity, due to interference with C1q binding to antibody-sensitized erythrocytes. These results indicate that the binding of fluidphase PTX3 to C1q may inhibit complement activation by competitive blocking of relevant interaction sites [79]. These data indicate that PTX3 may exert a dual role and contrasting effects on complement activation: it supports clearance of material that is able to bind PTX3, such as microbes, while, on the other hand, it may protect against unwanted complement activation in the fluid phase. The interaction with $\mathrm{Clq}$ and subsequent activation of complement are also modulated by the extent of PTX3 glycosylation, as demonstrated by the observation that removal of sialic acid or complete deglycosylation of the protein significantly increases its binding to C1q [74]. Consistent with this, PTX3 desialylation increases complement activation, as assessed by C3 and C4 deposition [74]. In this regard, it is worth noting that the oligosaccharides attached to the naturally expressed PTX3 from TNF $\alpha$-stimulated fibrosarcoma cells and LPSstimulated DCs have been reported to exhibit heterogeneity with regard to the relative content of terminal sialic acid and bi, tri, and tetra-antennary glycans [74]. These observations suggest that changes in the PTX3 glycosylation pattern might occur depending on the cell type and inflammatory context in which the protein is produced and might contribute to modulate its biological functions [74].

In 1999, Jarva showed that CRP can modulate the alternative pathway of complement activation through interaction with factor $\mathrm{H}$, the main soluble regulator of the alternative pathway [38]. PTX3 has also been described to interact with factor $\mathrm{H}$, thus enhancing factor $\mathrm{H}$ and iC3b deposition on apoptotic cells [81]. These observations suggest that the interaction of PTX3 with factor $\mathrm{H}$ modulates activation of the alternative pathway by promoting factor 

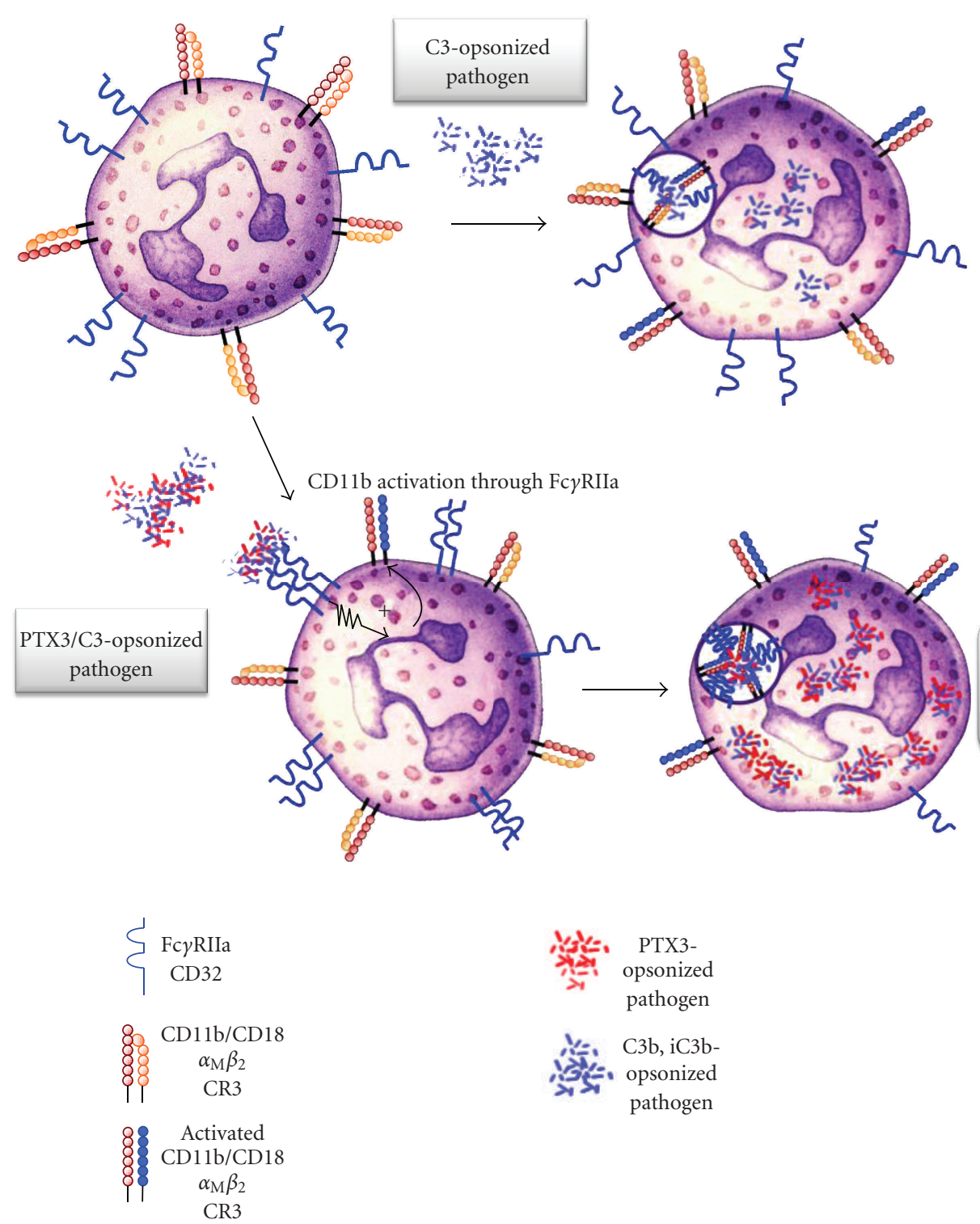

FIgure 3: Model of the PTX3-dependent opsonisation of A. fumigatus conidia. In the presence of PTX3-opsonized conidia, Fc $\gamma$ RIIA induces inside-out CD11b/CD18 activation, recruitment to the phagocytic cup, and amplification of C3b-opsonized conidia phagocytosis.

$\mathrm{H}$ deposition on PTX3-coated surfaces and preventing exaggerated complement activation [81].

Moreover, Ma and colleagues demonstrated that PTX3 interacts with L-Ficolin [84], similarly to CRP [85]. Ficolin2 could be affinity-isolated from human plasma on immobilized PTX3. Ficolin-2, but not Ficolin-1 or Ficolin-3, was shown to bind A. fumigates, and this binding was enhanced by PTX3 and vice versa. Consistent with this, PTX3 increases Ficolin-2-dependent complement deposition on the surface of $A$. fumigatus. Other components of the lectin pathway of complement interact with PTX3: for example, the mannose binding lectin (MBL) binds PTX3 and SAP probably via its collagen-like domain [86]. Formation of the MBL/PTX3 complex recruits C1q and enhances C4 and C3 deposition on and phagocytosis of Candida albicans [86]. Thus, components of the humoral innate immune system, which activate different complement pathways, cooperate and amplify microbial recognition and effector functions.

Together, these observations suggest a dual role for PTX3 in the regulation of complement-mediated immune responses. Interplay with key components of the three complement pathways (i.e., C1q, Ficolin-2, MBL, factor $\mathrm{H}$ ) points to PTX3 as an important player of the complex network of interactions that control complement functions.

4.4. PTX3 in Pathogen Recognition and Inflammation. PTX3 can interact with a number of different pathogens including selected fungi, virus, and bacteria. A specific binding has been observed to zymosan, Paracoccidioides brasiliensis, and conidia from Aspergillus fumigatus $[87,88]$. Additional interactions have been reported with 
some selected Gram-positive and Gram-negative bacteria, including Staphyloccocus aureus, Pseudomonas aeruginosa, Salmonella typhimurium, Streptococcus pneumoniae, and Neisseria meningitidis and with human and murine cytomegalovirus (CMV) and H3N2 influenza virus [87, 8991] (Figure 2). Among the tested microbial moieties, PTX3 binds Outer membrane protein A from Klebsiella pneumoniae (KpOmpA), a major component of the outer membrane of Gram-negative bacteria highly conserved throughout the enterobacteriaceae family [92], whereas it does not bind LPS, lipoteichoic acid (LTA), enterotoxin A and B, exotoxin A, and $\mathrm{N}$-Acetylmuramyl-L-Alanyl-D-Isoglutamine (MDP).

The recognition of a microbial component by PTX3 can amplify the inflammatory response, as reported for the interaction between PTX3 and the Outer membrane protein A of K. pneumoniae (KpOmpA). Several phagocyte PRMs cooperate when they sense whole organisms through different PAMPs. For instance, CD36 mediates binding and internalization of Gram-positive bacteria and cooperates with TLR2 and TLR6, which induce cytokine production [93]. Similarly, OmpA interacts with the scavenger receptor lectin-like oxidized low-density lipoprotein receptor-1 (LOX-1) and scavenger receptor expressed by endothelial cell-I (SREC-1), activates phagocytes through TLR2, and binds to PTX3, thus leading to amplification of the innate response to this microbial moiety (see below) $[92,94]$. This cooperation amongst simultaneously engaged PRMs leads to activation of diverse cellular signaling pathways as well as of the humoral arm of the innate immune system, which results in synergy and amplification of the innate responses to pathogens. In contrast to zymosan [88], PTX3 does not enhance the in vitro recognition of KpOmpA or the cell activation induced by KpOmpA. However, in vivo, PTX3 increases the local inflammation induced by KpOmpA, in terms of cell recruitment and proinflammatory cytokine production [92]. This effect is complement-dependent and is abrogated after treatment with complement inhibitors [94]. However, this amplification loop is not a general mechanism, since PTX3 does not modify the inflammatory response induced by LPS, a microbial moiety not recognized by PTX3 [94].

Genetically modified mice allowed investigating the in vivo relevance of microbes recognition by PTX3. Ptx $3^{-1-}$ mice are highly susceptible to invasive pulmonary aspergillosis, showing higher mortality [87]. PTX3-deficient neutrophils or dendritic cells and alveolar macrophages from $\mathrm{Ptx}^{-/-}$mice exhibit defective recognition and killing of conidia and the treatment with recombinant PTX3 or neutrophil-associated PTX3 reverses this phenotype $[62,87]$. This susceptibility is associated with a low protective $\mathrm{T}$ helper 1 (Th1) antifungal response coupled with an inappropriate Th2 response. Treatment with recombinant PTX3 restores the protective Th1 response demonstrating that PTX3 can participate in the tuning of immune responses [87, 90]. Moreover, in an experimental model of chronic granulomatous disease ( $p 47^{\text {phox-/-}}$ mice), PTX3 limits the Th17 response and the pathogenic inflammation induced by $A$. fumigatus infection. In both $p 47^{p h o x-/-}$ and $p 47^{p h o x+/+}$ mice, PTX3 reduces neutrophil counts and mononuclear cells recruitment to the lung parenchyma and bronchoalveolar lavage fluid. Furthermore, in $p 47^{\text {phox-/- }}$ mice infected by A. fumigatus, PTX3 modulates cytokine production and adaptive immunity through the enhancement of a Th1/Treg response associated with the restriction of a Th2/Th17 response [95].

PTX3-overexpressing macrophages exhibit increased phagocytosis of zymosan and $P$. brasiliensis than macrophages from wild-type mice [88]. Interestingly, in response to zymosan, ptx3-transgenic macrophages have an enhanced expression of dectin-1, the cellular receptor primarily involved in the interaction between macrophages and zymosan. Moreover, since zymosan induces PTX3 expression, dectin-1 upregulation promotes a positive feedback for this mechanism of phagocytosis [88].

Recent results indicate that PTX3 has therapeutic activity in chronic lung infections by $P$. aeruginosa. Chronic lung infections by $P$. aeruginosa strains are a major cause of morbidity and mortality in Cystic Fibrosis (CF) patients. C57BL/6 mice infected chronically with $P$. aeruginosa and treated with recombinant human PTX3 show an enhanced clearance of bacteria from the lungs, which is associated with reduced production of local proinflammatory cytokines, neutrophil recruitment in the airways and histopathological lesions (Moalli et al., unpublished results).

The role played by PTX3 in innate resistance to pathogens could also be exerted in an opsonisationindependent manner: in the case of K. pneumoniae infection, Soares and his collaborators could not demonstrate binding of PTX3 to K. pneumoniae; however, overexpression of PTX3 by transgenic mice during infection was associated with an enhanced ability to produce proinflammatory mediators, including NO and TNF $\alpha$, and, as a consequence, with protection or faster lethality, depending on the dose of inocula [96].

Bozza et al. studied the role of PTX3 in viral infections and found that PTX3 binds both human and murine cytomegalovirus (MCMV), reducing viral entry and infectivity in DC in vitro [89]. Consistently, PTX3-deficient mice are more susceptible to MCMV infection than PTX3 wild-type mice and PTX3 protects susceptible BALB/c mice from MCMV primary infection and reactivation in vivo as well as Aspergillus superinfection. This occurs through the activation of interferon regulatory factor 3 (IRF3) in DC via TLR9/MyD88-independent viral recognition and the promotion of the IL-12/IFN- $\gamma$-dependent effector pathway [89].

Finally, human and murine PTX3 binds influenza virus $(\mathrm{H} 3 \mathrm{~N} 2)$ through the interaction between the viral haemagglutinin glycoprotein and the sialic acid residue present on the glycosidic moiety of PTX3. PTX3 inhibits virusinduced haemagglutination and viral neuraminidase activity and neutralizes the virus infectivity. Consistently, $p t \times 3^{-/-}$ mice are more susceptible than wild-type mice to influenza virus infection. Treatment with recombinant PTX3 reduces mortality and the viral load [91]. However, it has been recently reported that both seasonal and pandemic H1N1 influenza A viruses were resistant to the antiviral activity of PTX3 [97]. 
We recently investigated the molecular mechanisms underlying the opsonic activity of PTX3 and demonstrated that PTX3 enhances the recognition and phagocytosis of conidia by neutrophils through a Fc $\gamma$ receptor II (Fc $\gamma$ RII)and complement-dependent mechanism [78]. Indeed, PTX3 modulates different effector pathways involved in innate resistance to A. fumigatus, including the classic, the alternative, and the lectin pathway of complement activation, as stated above $[71,79,81,84]$ or through the promotion of phagocytosis by interacting with Fc $\gamma$ Rs, which have been proposed as pentraxin receptors [45]. Our findings demonstrated that phagocytosis of PTX3-opsonized conidia is significantly increased in the presence of complement. The complement component C3 in particular plays a key role in Aspergillus conidia phagocytosis and PTX3 amplifies the complement-dependent effects on phagocytosis (Figure 3 ). In contrast, in vitro and in vivo data suggest that PTX3 plays its role in facilitating conidia phagocytosis independently of the interaction with C1q. Indeed, recombinant PTX3 has a therapeutic effect in a model of aspergillosis also in $\mathrm{C} 1 \mathrm{q}$-deficient mice, rescuing their defective resistance to the infection [87]. Moreover, in the presence of PTX3-opsonized conidia, CD11b activation, internalization, recruitment to the phagocytic cup, and CD11b-dependent phagocytosis are increased. Previous studies have provided evidence that Fc $\gamma$ Rs-derived signals induce activation of CR3 (CD11b/CD18) [98]. Specifically, Fc $\gamma$ Rs stimulation in macrophages promotes CR3 clustering into high-avidity complexes in phagocytic cups by a mechanism involving release of integrins from their cytoskeletal constraints, thus enhancing their lateral diffusion. PTX3 loses its therapeutic activity against $A$. fumigatus in FcR $\gamma$-deficient mice, which lack signaling from any functional activating Fc $\gamma$ Rs. On the same line, CD11b recruitment in the phagocytic cup is defective in PTX3- and FcR $\gamma$-deficient PMN and is rescued by recombinant PTX3 in PTX3-deficient PMN but not in FcR $\gamma$-deficient PMN [78]. These results suggest that both endogenous, neutrophil-stored, and exogenous (e.g., in a therapeutic setting) PTX3 act via the same complement/CD $11 \mathrm{~b} / \mathrm{Fc} \gamma$ Rs-dependent pathway.

The relevance in humans of data obtained in animals on the role of PTX3 in infections has been demonstrated by Olesen and colleagues who recently analyzed the role of polymorphisms within the PTX3 gene in pulmonary tuberculosis (TBC) and showed that the frequency of specific PTX3 haplotypes is significantly different in TBC patients as compared to healthy individuals [99]. In addition, recent observations by Chiarini and colleagues have shown that polymorphisms in the PTX3 gene correlate with the risk of Pseudomonas aeruginosa infections in CF patients [100].

In conclusion, PTX3 is released by PMNs and produced by DCs, neighbouring macrophages, and other cell types upon TLR engagement or pathogen recognition, recognizes microbial moieties, opsonises fungi, binds selected Grampositive and Gram-negative bacteria, and viruses, and activates complement. Opsonisation results in facilitated pathogen recognition (increased phagocytosis and killing) and activation of innate immune cells (increased cytokine and nitric oxide production); moreover, opsonisation by
PTX3 is likely involved in the activation of an appropriate adaptive immune response (DC maturation and polarization). Again, as discussed above, all these properties suggest that this long pentraxin behaves as a functional ancestor of antibodies.

Data obtained in different models in vivo demonstrated that PTX3 is involved in modulating inflammation in sterile conditions, for instance, in acute myocardial infarction and atherosclerosis [101]. We recently demonstrated that PTX3 selectively binds P-selectin via its N-linked glycosidic moiety inhibiting leukocyte rolling on endothelium. Moreover, exogenously administered PTX3 and endogenous PTX3 released from hematopoietic cells provide a negative feedback loop that prevents excessive P-selectin-dependent recruitment of neutrophils in a model of acute lung injury (ALI), pleurisy, and mesenteric inflammation [80]. Therefore, these data suggests that PTX3 produced by activated leukocytes might locally dampen neutrophil recruitment and regulate inflammation. In keeping with this, Liu and colleagues suggested that PTX3 plays a protective role in the pathogenesis of acute lung injury (ALI) and the lack of PTX3 may enhance neutrophil recruitment, cell death, and inflammatory responses in the LPS instillation-induced ALI [102].

4.5. Self versus Modified Self-Discrimination. Apoptosis is the process of controlled cell death that physiologically occurs in embryogenesis, tissue turnover, and resolution of inflammation. Rapid and efficient clearance of apoptotic cells by phagocytes is necessary to avoid loss of cell integrity, activation of bystander cells, and tissue damage that are induced by the proinflammatory contents of dying cells [103]. PRMs can opsonise apoptotic cells and modulate their recognition by phagocytes.

Both PTX3 and the short pentraxins SAP and CRP have been involved in the clearance of apoptotic cells, however with opposing functional effects [103]. While CRP and SAP opsonise apoptotic cells and promote their clearance, the binding of PTX3 to dying cells results in inhibition of their elimination [104-106]. In fact, the interaction between PTX3 and $\mathrm{Clq}$ prevents the binding of $\mathrm{Clq}$ to apoptotic cells, thus causing a defective recognition of these cellular targets by phagocytes [107]. Moreover, PTX3 inhibits the crosspresentation of apoptotic cell-derived antigens of self-, viral, or tumoral origin to autoreactive $\mathrm{CD}^{+} \mathrm{T}$ cells [108]. It has been reported that opsonisation of apoptotic cells by factor $\mathrm{H}$ limits the complement-mediated lysis of these cells [109]. Through its binding to factor $\mathrm{H}$, PTX3 promotes recruitment of this complement component to the surface of dying cells, therefore, playing a role also as a negative modulator of the alternative pathway of complement activation in injured tissues [81].

However, we have described that endogenous PTX3 translocates to the plasma membrane of late apoptotic neutrophils through a process that involves fusion of granules and apoptotic cell membrane. The translocated PTX3 accumulates in blebs of the plasma membrane, where it acts as an "eat-me" molecule in promoting rather than inhibiting 
the clearance of apoptotic neutrophils by phagocytes [110]. Therefore, membrane-associated PTX3 favours phagocytosis of late apoptotic neutrophils, as opposed to the soluble form of PTX3 that inhibits this process, as discussed above.

The apparent contradiction between the two opposing functional effects of PTX3 might be resolved if the context of the protein production is taken into account. In fact, on one hand, cell-bound PTX3 might serve to enhance the elimination of apoptotic cells before loss of their cellmembrane permeability and release of self-antigens and alarmins $[110,111]$. On the other, rapid production and secretion of PTX3 during inflammation might avoid capture of apoptotic cells in a proinflammatory setting that is likely to trigger an immune response against self-antigens [103]. Data obtained in vivo actually support the hypothesis that PTX3 plays a protective role in a murine model of systemic lupus erythematosus (Lech et al., unpublished results).

4.6. PTX3 Role in Tissue Remodelling. In addition to the biological activities that PTX3 exerts as a PRM of the innate immune system, new functional roles have been described for this long pentraxin in processes of tissue remodelling, including extracellular matrix deposition, angiogenesis, and restenosis.

Mammalian ovulation is a highly regulated, inflammation-like process that involves extensive tissue remodelling [112]. Ptx $^{-/-}$mice generated by homologous recombination display a severe deficiency in female fertility [113]. This has been attributed to defective assembly of the viscoelastic hyaluronan- (HA-) rich matrix that forms around the oocyte in the preovulatory follicle (namely, the cumulus oophorus complex, COC), where PTX3 is produced by cumulus cells and localizes within the matrix [114]. Beside PTX3, other molecules are required for effective incorporation of HA into the cumulus matrix, including the HA-binding proteins TSG-6 and the serum proteoglycan $\mathrm{I} \alpha \mathrm{I}[112,115,116]$. The current literature supports the hypothesis that heavy chains (HCs) from $\mathrm{I} \alpha \mathrm{I}$ become covalently attached to HA (i.e., to form HC.HA complexes) through reactions involving TSG6 , which acts as both a cofactor and catalyst $[117,118]$. The resulting HC·HA complexes are believed to be crosslinked by PTX3, where the long pentraxin can establish multiple contacts to $\mathrm{HCs}$, thus providing structural integrity to the cumulus matrix $[77,82]$. The finding that PTX3 is an essential component of the cumulus oophorus extracellular matrix raises the possibility that this protein might have a similar localization and structural function in other HA-enriched inflammatory tissues, such as in rheumatoid arthritis, where TSG- 6 and $\mathrm{I} \alpha \mathrm{I}$ are also present [118]. This hypothesis is corroborated by the observation that TSG6 and PTX3 colocalize in the inflammatory infiltrates and endothelial cells of inflamed tissues [63].

Angiogenesis is the generation of new blood vessels from the endothelium of existing vasculature. This process, that occurs under normal physiological conditions in growth and development, and is required for successful wound healing, is regulated by the balance between pro- and antiangiogenic factors [119]. FGF2 is a major angiogenic inducer that promotes cell proliferation, chemotaxis, and protease production in cultured endothelial cells (ECs) and neovascularisation in vivo during wound healing, inflammation, tumour growth, and atherosclerosis [120]. PTX3 recognizes FGF2 with high affinity and specificity, where both proteins are produced by elements of the vessel wall (i.e., ECs and smooth muscle cells, SMCs) during inflammation [121, 122]. PTX3 binding to FGF2 results in inhibition of the FGF2dependent EC proliferation in vitro and angiogenesis in vivo [121]. PTX3 produced by ECs and inflammatory cells may, therefore, affect the autocrine and paracrine activity of FGF2 on endothelium, providing a mechanism for tuning the neovascularisation process.

FGF2 is long known to promote survival, proliferation, and migration of SMCs expressing tyrosine-kinase FGF receptors (FGFRs) both in vitro and in vitro [120]. SMCs activation is a key feature of restenosis, the process of blood vessel narrowing that frequently occurs after coronary angioplasty [123]. It has been reported that PTX3 prevents the binding of FGF2 to FGFRs in human coronary artery SMCs, thus inhibiting the endogenous FGF2-dependent SMCs proliferation and suppressing the mitogenic and chemotactic activity exerted by exogenous FGF2 on these cells [122]. These observations suggest that PTX3 may represent a potent inhibitor of the autocrine and paracrine stimulation exerted by FGF2 on SMCs and point to a novel therapeutic role of PTX3 in the treatment of restenosis after angioplasty $[124,125]$.

PTX3 expression has been recently reported in different tumours, and increasing evidence suggests a potential clinical use of this pentraxin as a novel cancer biomarker [126-130]. However, the role of PTX3 in oncogenesis is still unclear and certainly requires further investigations.

4.7. Diagnostic and Prognostic Potential of PTX3 in Infectious Disorders. CRP has been extensively used clinically for over 75 years as a nonspecific systemic marker of infection, inflammation, and tissue damage. Given the rapid production of PTX3 during inflammation, PTX3 is a candidate marker for inflammatory, infectious, and cardiovascular pathologies (reviewed in $[8,101,131])$. PTX3 behaves as an acute-phase protein since its blood levels, low in normal conditions (about $25 \mathrm{ng} / \mathrm{mL}$ in the mouse, $<2 \mathrm{ng} / \mathrm{mL}$ in humans), increase rapidly (with a maximum at $6-8 \mathrm{~h}$ ) and dramatically $(200-800 \mathrm{ng} / \mathrm{mL})$ during endotoxic shock, sepsis, and other inflammatory and infectious conditions.

Increased levels of PTX3 have been observed in diverse infectious disorders including sepsis and septic shock, meningococcal disease, tuberculosis, and dengue infection [132-135]. Pulmonary tuberculosis patients were reported to present higher levels of plasma PTX3 as compared to healthy controls. Moreover, at the end of treatment, cured patients showed reduction of PTX3 titers whereas the protein level increased further in patients with treatment failure [132]. High concentrations of PTX 3 were also found in dengue virus patients, where the highest titers were observed within 7 days of onset of symptoms. Interestingly, PTX3 levels were strikingly higher than those of CRP levels, suggesting that 
PTX3 might be a better marker of infection than C-reactive protein in dengue [133]. High plasma concentrations of PTX3 were seen at admission in patients with meningococcal disease, where the protein proved to be an early indicator of shock in patients with severe disease, despite its levels did not correlate with severity of the pathology [134]. In patients with severe sepsis or septic shock, high levels of plasma PTX3 over the first five days from admission have been associated with disease severity, secondary organ failures, and mortality. Moreover, PTX3 levels were shown to better correlate with severity of the disease and organ dysfunctions than other measured mediators (i.e., TNF $\alpha$, IL-6, and CRP) [135].

It has been reported that the concentration of circulating PTX3 increases during pregnancy, a condition that has been associated with inflammation. Higher maternal PTX3 levels have been observed in pregnancies complicated by preeclampsia, which represents the clinical manifestation of an endothelial dysfunction that is part of an excessive maternal inflammatory response to pregnancy $[136,137]$. PTX3 plasma and vaginal levels increase also during pregnancy complicated by spontaneous preterm delivery, in particular in cases of placenta vasculopathy [138]. Furthermore, recent studies have reported the presence of PTX3 in the amniotic fluid and elevated protein concentrations in intra-amniotic inflammation and infection $[139,140]$. In contrast, the increased titres of maternal plasma PTX3 observed during labor are not related to either intra-amniotic inflammation or infection [141].

Collectively, these studies demonstrate that measurement of PTX3 may help monitoring disease activity and efficacy of therapy and might have a prognostic value.

\section{Concluding Remarks}

Pentraxins are essential components of the humoral arm of innate immunity, as such, they participate in recognition of and response to pathogens and tissue damage, in coordination with the cellular arm. The short pentraxin CRP was the first identified soluble pattern recognition molecule. Yet, in spite of its widespread use as a diagnostic tool in the clinic, its in vivo function has not been unambiguously defined, mostly due to the diverging regulation of its expression in the evolution from mouse to man. In contrast, gene targeting of the prototypic, evolutionarily conserved, long pentraxin PTX3 has unequivocally defined the role of this molecule in innate immunity and inflammation. The recent literature has further clarified the structure, regulation, microbial recognition, and in vivo functions of PTX3. As a component of the humoral arm of innate immunity, PTX3 plays a similar role to that exerted by antibodies in adaptive immunity, including complement activation, opsonisation, and glycosylation-dependent regulation of inflammation. Pathogen sensing and elimination are major functional roles of PTX3, where this long pentraxin facilitates recognition of microbes and microbial moieties, and promotes activation of innate immune cells. Also, the available evidence suggests that PTX3 not only acts as a PRM, but also plays prominent roles at the cross-road between vascular biology, female fertility, and discrimination between self, nonself, and modified self. Furthermore, clinical observations point to PTX3 as an early marker of infection and inflammation that rapidly reflects the physiopathological state of tissues and vessel wall.

\section{Acknowledgments}

The contributions of the European Commission ("MUGEN" LSHG-CT-2005-005203, “TOLERAGE” 2008-02156), European Research Council (project HIIS), Ministero dell'Istruzione, Università e della Ricerca (MIUR) (project FIRB), Telethon (Telethon Grant no. GGP05095), fondazione CARIPLO (Project Nobel and Project 2009-2582), Ministero della Salute (Ricerca finalizzata), the Italian Association for Cancer Research (AIRC), and Scuola Europea di Medicina Molecolare (SEMM) are gratefully acknowledged. F. Moalli, S. Jaillon, A. Inforzato equally contributed to this work

\section{References}

[1] A. Iwasaki and R. Medzhitov, "Regulation of adaptive immunity by the innate immune system," Science, vol. 327, no. 5963, pp. 291-295, 2010.

[2] J. E. Murphy, P. R. Tedbury, S. Homer-Vanniasinkam, J. H. Walker, and S. Ponnambalam, "Biochemistry and cell biology of mammalian scavenger receptors," Atherosclerosis, vol. 182, no. 1, pp. 1-15, 2005.

[3] S. Akira, S. Uematsu, and O. Takeuchi, "Pathogen recognition and innate immunity," Cell, vol. 124, no. 4, pp. 783-801, 2006.

[4] E. Meylan, J. Tschopp, and M. Karin, "Intracellular pattern recognition receptors in the host response," Nature, vol. 442, no. 7098, pp. 39-44, 2006.

[5] B. Bottazzi, A. Doni, C. Garlanda, and A. Mantovani, "An integrated view of humoral innate immunity: pentraxins as a paradigm," Annual Review of Immunology, vol. 28, pp. 157$183,2010$.

[6] B. Bottazzi, C. Garlanda, G. Salvatori, P. Jeannin, A. Manfredi, and A. Mantovani, "Pentraxins as a key component of innate immunity," Current Opinion in Immunology, vol. 18, no. 1, pp. 10-15, 2006.

[7] U. Holmskov, S. Thiel, and J. C. Jensenius, "Collectins and ficolins: humoral lectins of the innate immune defense," Annual Review of Immunology, vol. 21, pp. 547-578, 2003.

[8] L. Deban, S. Jaillon, C. Garlanda, B. Bottazzi, and A. Mantovani, "Pentraxins in innate immunity: lessons from PTX3," Cell and Tissue Research, vol. 343, no. 1, pp. 237-249, 2010.

[9] C. Garlanda, B. Bottazzi, A. Bastone, and A. Mantovani, "Pentraxins at the crossroads between innate immunity, inflammation, matrix deposition, and female fertility," Annual Review of Immunology, vol. 23, pp. 337-366, 2005.

[10] T. J. Abernethy and O. T. Avery, "The occurence during acute infections of a protein non normally present in the blood. I. Distribution of the reactive protein in patients' sera and the effect of calcium on the flocculation reaction with $\mathrm{C}$. Polysaccharide of Pneumococcus," Journal of Experimental Medicine, vol. 73, pp. 173-182, 1941.

[11] W. S. Tillett and T. Francis, "Serological reactions in pneumonia with a non-protein somatic fraction of pneumococcus," Journal of Experimental Medicine, vol. 52, pp. 561-571, 1930. 
[12] J. Emsley, H. E. White, B. P. O'Hara et al., "Structure of pentameric human serum amyloid P component," Nature, vol. 367, no. 6461, pp. 338-345, 1994.

[13] A. K. Shrive, A. M. Metcalfe, J. R. Cartwright, and T. J. Greenhough, "C-reactive protein and SAP-like pentraxin are both present in Limulus polyphemus haemolymph: crystal structure of Limulus SAP," Journal of Molecular Biology, vol. 290, no. 5, pp. 997-1008, 1999.

[14] P. B. Armstrong, S. Swarnakar, S. Srimal et al., "A cytolytic function for a sialic acid-binding lectin that is a member of the pentraxin family of proteins," Journal of Biological Chemistry, vol. 271, no. 25, pp. 14717-14721, 1996.

[15] T. Y. Liu, F. A. Robey, and C. M. Wang, "Structural studies on C-reactive protein," Annals of the New York Academy of Sciences, vol. 389, pp. 151-162, 1982.

[16] N. Rubio, P. M. Sharp, M. Rits, K. Zahedi, and A. S. Whitehead, "Structure, expression, and evolution of guinea pig serum amyloid P component and C-reactive protein," Journal of Biochemistry, vol. 113, no. 3, pp. 277-284, 1993.

[17] B. Bottazzi, C. Garlanda, A. Cotena et al., "The long pentraxin PTX3 as a prototypic humoral pattern recognition receptor: interplay with cellular innate immunity," Immunological Reviews, vol. 227, no. 1, pp. 9-18, 2009.

[18] M. B. Pepys and G. M. Hirschfield, "C-reactive protein: a critical update," Journal of Clinical Investigation, vol. 111, no. 12, pp. 1805-1812, 2003.

[19] M. S. Reid and C. P. Blobel, "Apexin, an acrosomal pentaxin," Journal of Biological Chemistry, vol. 269, no. 51, pp. 3261532620, 1994.

[20] I. A. Omeis, Y. C. Hsu, and M. S. Perin, "Mouse and human neuronal pentraxin 1 (NPTX1): conservation, genomic structure, and chromosomal localization," Genomics, vol. 36, no. 3, pp. 543-545, 1996.

[21] Y. C. Hsu and M. S. Perin, "Human neuronal pentraxin II (NPTX2): conservation, genomic structure, and chromosomal localization," Genomics, vol. 28, no. 2, pp. 220-227, 1995.

[22] D. C. Dodds, I. A. Omeis, S. J. Cushman, J. A. Helms, and M. S. Perin, "Neuronal pentraxin receptor, a novel putative integral membrane pentraxin that interacts with neuronal pentraxin 1 and 2 and taipoxin- associated calcium-binding protein 49," Journal of Biological Chemistry, vol. 272, no. 34, pp. 21488-21494, 1997.

[23] Y. Martinez de la Torre, M. Fabbri, S. Jaillon et al., "Evolution of the pentraxin family: the new entry PTX4," Journal of Immunology, vol. 184, pp. 5055-5064, 2010.

[24] A. J. Szalai, "The antimicrobial activity of C-reactive protein," Microbes and Infection, vol. 4, no. 2, pp. 201-205, 2002.

[25] A. J. Szalai, D. E. Briles, and J. E. Volanakis, "Human C-reactive protein is protective against fatal Streptococcus pneumoniae infection in transgenic mice," Journal of Immunology, vol. 155, no. 5, pp. 2557-2563, 1995.

[26] C. R. Hind, P. M. Collins, D. Renn et al., "Binding specificity of serum amyloid $\mathrm{P}$ component for the pyruvate acetal of galactose," Journal of Experimental Medicine, vol. 159, pp. 1058-1069, 1984.

[27] C. R. Hind, P. M. Collins, M. L. Baltz, and M. B. Pepys, "Human serum amyloid P component, a circulating lectin with specificity for the cyclic 4,6-pyruvate acetal of galactose. Interactions with various bacteria," Biochemical Journal, vol. 225, no. 1, pp. 107-111, 1985.

[28] M. Noursadeghi, M. C. Bickerstaff, J. R. Gallimore, J. Herbert, J. Cohen, and M. B. Pepys, "Role of serum amyloid $\mathrm{P}$ component in bacterial infection: protection of the host or protection of the pathogen," Proceedings of the National
Academy of Sciences of the United States of America, vol. 97, no. 26, pp. 14584-14589, 2000.

[29] O. Andersen, K. Vilsgaard Ravn, I. Juul Sørensen, G. Jonson, E. Holm Nielsen, and S. E. Svehag, "Serum amyloid P component binds to influenza A virus haemagglutinin and inhibits the virus infection in vitro," Scandinavian Journal of Immunology, vol. 46, no. 4, pp. 331-337, 1997.

[30] C. J. de Haas, M. E. van der Tol, K. P. Van Kessel, J. Verhoef, and J. A. Van Strijp, "A synthetic lipopolysaccharide-binding peptide based on amino acids 27-39 of serum amyloid $\mathrm{P}$ component inhibits lipopolysaccharide-induced responses in human blood," Journal of Immunology, vol. 161, no. 7, pp. 3607-3615, 1998.

[31] C. J. de Haas, E. M. van Leeuwen, T. van Bommel, J. Verhoef, K. P. van Kessel, and J. A. van Strijp, "Serum amyloid $\mathrm{P}$ component bound to gram-negative bacteria prevents lipopolysaccharide-mediated classical pathway complement activation," Infection and Immunity, vol. 68, no. 4, pp. 17531759, 2000.

[32] L. T. Roumenina, M. M. Ruseva, A. Zlatarova et al., "Interaction of C1q with IgG1, C-reactive protein and pentraxin 3: mutational studies using recombinant globular head modules of human C1q A, B, and C chains," Biochemistry, vol. 45, no. 13, pp. 4093-4104, 2006.

[33] M. V. Suresh, S. K. Singh, D. A. Ferguson Jr, and A. Agrawal, "Human C-reactive protein protects mice from Streptococcus pneumoniae infection without binding to pneumococcal C-polysaccharide," Journal of Immunology, vol. 178, no. 2, pp. 1158-1163, 2007.

[34] A. J. Szalai, J. L. VanCott, J. R. McGhee, J. E. Volanakis, and W. H. Benjamin Jr., "Human C-reactive protein is protective against fatal Salmonella enterica serovar typhimurium infection in transgenic mice," Infection and Immunity, vol. 68, no. 10, pp. 5652-5656, 2000.

[35] M. V. Suresh, S. K. Singh, D. A. Ferguson Jr, and A. Agrawal, "Role of the property of C-reactive protein to activate the classical pathway of complement in protecting mice from pneumococcal infection," Journal of Immunology, vol. 176, no. 7, pp. 4369-4374, 2006.

[36] P. M. Ng, A. Le Saux, C. M. Lee et al., "C-reactive protein collaborates with plasma lectins to boost immune response against bacteria," The EMBO Journal, vol. 26, no. 14, pp. 3431-3440, 2007.

[37] M. Tanio, K. Wakamatsu, and T. Kohno, "Binding site of Creactive protein on M-ficolin," Molecular Immunology, vol. 47, no. 2-3, pp. 215-221, 2009.

[38] H. Jarva, T. S. Jokiranta, J. Hellwage, P. F. Zipfel, and S. Meri, "Regulation of complement activation by C-reactive protein: targeting the complement inhibitory activity of factor $\mathrm{H}$ by an interaction with short consensus repeat domains 7 and 811," Journal of Immunology, vol. 163, no. 7, pp. 3957-3962, 1999.

[39] M. Mihlan, S. Stippa, M. Józsi, and P. F. Zipfel, "Monomeric CRP contributes to complement control in fluid phase and on cellular surfaces and increases phagocytosis by recruiting factor H," Cell Death and Differentiation, vol. 16, no. 12, pp. 1630-1640, 2009.

[40] A. I. Okemefuna, R. Nan, A. Miller, J. Gor, and S. J. Perkins, "Complement factor $\mathrm{H}$ binds at two independent sites to Creactive protein in acute phase concentrations," Journal of Biological Chemistry, vol. 285, no. 2, pp. 1053-1065, 2010.

[41] A. J. Nauta, M. R. Daha, C. van Kooten, and A. Roos, "Recognition and clearance of apoptotic cells: a role for 
complement and pentraxins," Trends in Immunology, vol. 24, no. 3, pp. 148-154, 2003.

[42] D. Bharadwaj, C. Mold, E. Markham, and T. W. Du Clos, "Serum amyloid $\mathrm{P}$ component binds to Fc gamma receptors and opsonizes particles for phagocytosis," Journal of Immunology, vol. 166, no. 11, pp. 6735-6741, 2001.

[43] D. Bharadwaj, M. P. Stein, M. Volzer, C. Mold, and T. W. $\mathrm{Du}$ Clos, "The major receptor for C-reactive protein on leukocytes is Fc gamma receptor II," Journal of Experimental Medicine, vol. 190, no. 4, pp. 585-590, 1999.

[44] C. Mold, R. Baca, and T. W. Du Clos, "Serum amyloid P component and C-reactive protein opsonize apoptotic cells for phagocytosis through Fc gamma receptors," Journal of Autoimmunity, vol. 19, no. 3, pp. 147-154, 2002.

[45] J. Lu, L. L. Marnell, K. D. Marjon, C. Mold, T. W. Du Clos, and P. D. Sun, "Structural recognition and functional activation of FcgammaR by innate pentraxins," Nature, vol. 456, no. 7224, pp. 989-992, 2008.

[46] F. Breviario, E. M. D’Aniello, J. Golay et al., "Interleukin1-inducible genes in endothelial cells. Cloning of a new gene related to $\mathrm{C}$-reactive protein and serum amyloid $\mathrm{P}$ component," Journal of Biological Chemistry, vol. 267, no. 31, pp. 22190-22197, 1992.

[47] A. Altmeyer, L. Klarapfer, A. R. Goodman, and J. Vilcek, "Promoter structure and transcriptional activation of the murine TSG-14 gene encoding a tumor necrosis factor/interleukin-1-inducible pentraxin protein," Journal of Biological Chemistry, vol. 270, no. 43, pp. 25584-25590, 1995.

[48] A. Basile, A. Sica, E. D'Aniello et al., "Characterization of the promoter for the human long pentraxin PTX3. Role of NFkappaB in tumor necrosis factor-alpha and interleukin-1beta regulation," Journal of Biological Chemistry, vol. 272, no. 13, pp. 8172-8178, 1997.

[49] G. W. Lee, T. H. Lee, and J. Vilcek, "TSG-14, a tumor necrosis factor- and IL-1-inducible protein, is a novel member of the pentaxin family of acute phase proteins," Journal of Immunology, vol. 150, no. 5, pp. 1804-1812, 1993.

[50] A. Abderrahim-Ferkoune, O. Bezy, C. Chiellini et al., "Characterization of the long pentraxin PTX3 as a TNFalphainduced secreted protein of adipose cells," Journal of Lipid Research, vol. 44, no. 5, pp. 994-1000, 2003.

[51] A. Doni, G. Peri, M. Chieppa et al., "Production of the soluble pattern recognition receptor PTX3 by myeloid, but not plasmacytoid, dendritic cells," European Journal of Immunology, vol. 33, no. 10, pp. 2886-2893, 2003.

[52] C. C. dos Santos, B. Han, C. F. Andrade et al., "DNA microarray analysis of gene expression in alveolar epithelial cells in response to TNFalpha, LPS, and cyclic stretch," Physiological Genomics, vol. 19, pp. 331-342, 2004.

[53] A. R. Goodman, D. E. Levy, L. F. Reis, and J. Vilcek, "Differential regulation of TSG-14 expression in murine fibroblasts and peritoneal macrophages," Journal of Leukocyte Biology, vol. 67, no. 3, pp. 387-395, 2000.

[54] B. Han, M. Mura, C. F. Andrade et al., "TNFalpha-induced long pentraxin PTX3 expression in human lung epithelial cells via JNK," Journal of Immunology, vol. 175, no. 12, pp. 8303-8311, 2005.

[55] M. Introna, V. V. Alles, M. Castellano et al., "Cloning of mouse ptx3, a new member of the pentraxin gene family expressed at extrahepatic sites," Blood, vol. 87, no. 5, pp. 1862-1872, 1996.

[56] A. J. Nauta, S. de Haij, B. Bottazzi et al., "Human renal epithelial cells produce the long pentraxin PTX3," Kidney International, vol. 67, no. 2, pp. 543-553, 2005.
[57] H. Jeon, S. Lee, W. H. Lee, and K. Suk, "Analysis of glial secretome: the long pentraxin PTX3 modulates phagocytic activity of microglia," Journal of Neuroimmunology, vol. 229, no. 1-2, pp. 63-72, 2010.

[58] S. Amatschek, E. Kriehuber, W. Bauer et al., "Blood and lymphatic endothelial cell-specific differentiation programs are stringently controlled by the tissue environment," Blood, vol. 109, no. 11, pp. 4777-4785, 2007.

[59] M. Sironi, A. Conti, S. Bernasconi et al., "Generation and characterization of a mouse lymphatic endothelial cell line," Cell and Tissue Research, vol. 325, no. 1, pp. 91-100, 2006.

[60] N. Wick, P. Saharinen, J. Saharinen et al., "Transcriptomal comparison of human dermal lymphatic endothelial cells ex vivo and in vitro," Physiological Genomics, vol. 28, no. 2, pp. 179-192, 2007.

[61] V. V. Alles, B. Bottazzi, G. Peri, J. Golay, M. Introna, and A. Mantovani, "Inducible expression of PTX3, a new member of the pentraxin family, in human mononuclear phagocytes," Blood, vol. 84, no. 10, pp. 3483-3493, 1994.

[62] S. Jaillon, G. Peri, Y. Delneste et al., "The humoral pattern recognition receptor PTX3 is stored in neutrophil granules and localizes in extracellular traps," Journal of Experimental Medicine, vol. 204, no. 4, pp. 793-804, 2007.

[63] V. Maina, A. Cotena, A. Doni et al., "Coregulation in human leukocytes of the long pentraxin PTX3 and TSG-6," Journal of Leukocyte Biology, vol. 86, no. 1, pp. 123-132, 2009.

[64] A. Savchenko, M. Imamura, R. Ohashi et al., "Expression of pentraxin 3 (PTX3) in human atherosclerotic lesions," Journal of Pathology, vol. 215, no. 1, pp. 48-55, 2008.

[65] M. Klouche, N. Brockmeyer, C. Knabbe, and S. Rose-John, "Human herpesvirus 8-derived viral IL-6 induces PTX3 expression in Kaposi's sarcoma cells," AIDS, vol. 16, no. 8, pp. F9-F18, 2002.

[66] L. Malaguarnera, M. R. Pilastro, L. Vicari, R. Di Marco, M. Malaguarnera, and A. Messina, "PTX3 gene expression in Castleman's disease," European Journal of Haematology, vol. 64, no. 2, pp. 132-134, 2000.

[67] A. Doni, M. Michela, B. Bottazzi et al., "Regulation of PTX3, a key component of humoral innate immunity in human dendritic cells: stimulation by IL-10 and inhibition by IFNgamma," Journal of Leukocyte Biology, vol. 79, no. 4, pp. 797802, 2006.

[68] M. Salio, S. Chimenti, N. De Angelis et al., "Cardioprotective function of the long pentraxin PTX3 in acute myocardial infarction," Circulation, vol. 117, no. 8, pp. 1055-1064, 2008.

[69] G. D. Norata, P. Marchesi, A. Pirillo et al., "Long pentraxin 3, a key component of innate immunity, is modulated by highdensity lipoproteins in endothelial cells," Arteriosclerosis, Thrombosis, and Vascular Biology, vol. 28, no. 5, pp. 925-931, 2008.

[70] A. Doni, G. Mantovani, C. Porta et al., "Cell-specific regulation of PTX3 by glucocorticoid hormones in hematopoietic and nonhematopoietic cells," Journal of Biological Chemistry, vol. 283, no. 44, pp. 29983-29992, 2008.

[71] B. Bottazzi, V. Vouret-Craviari, A. Bastone et al., "Multimer formation and ligand recognition by the long pentraxin PTX3. Similarities and differences with the short pentraxins C-reactive protein and serum amyloid P component," Journal of Biological Chemistry, vol. 272, no. 52, pp. 32817-32823, 1997.

[72] M. Presta, M. Camozzi, G. Salvatori, and M. Rusnati, "Role of the soluble pattern recognition receptor PTX3 in vascular biology," Journal of Cellular and Molecular Medicine, vol. 11, no. 4, pp. 723-738, 2007. 
[73] B. Bottazzi, A. Bastone, A. Doni et al., "The long pentraxin PTX3 as a link among innate immunity, inflammation, and female fertility," Journal of Leukocyte Biology, vol. 79, no. 5, pp. 909-912, 2006.

[74] A. Inforzato, G. Peri, A. Doni et al., "Structure and function of the long pentraxin PTX3 glycosidic moiety: fine-tuning of the interaction with $\mathrm{Clq}$ and complement activation," Biochemistry, vol. 45, no. 38, pp. 11540-11551, 2006.

[75] A. R. Goodman, T. Cardozo, R. Abagyan, A. Altmeyer, H. G. Wisniewski, and J. Vilček, "Long pentraxins: an emerging group of proteins with diverse functions," Cytokine and Growth Factor Reviews, vol. 7, no. 2, pp. 191-202, 1996.

[76] M. Camozzi, M. Rusnati, A. Bugatti et al., "Identification of an antiangiogenic FGF2-binding site in the $\mathrm{N}$ terminus of the soluble pattern recognition receptor PTX3," Journal of Biological Chemistry, vol. 281, no. 32, pp. 22605-22613, 2006.

[77] L. Scarchilli, A. Camaioni, B. Bottazzi et al., "PTX3 interacts with inter-alpha-trypsin inhibitor: implications for hyaluronan organization and cumulus oophorus expansion," Journal of Biological Chemistry, vol. 282, no. 41, pp. 30161-30170, 2007.

[78] F. Moalli, A. Doni, L. Deban et al., "Role of complement and Fc $\{$ gamma $\}$ receptors in the protective activity of the long pentraxin PTX3 against Aspergillus fumigatus," Blood, vol. 116, no. 24, pp. 5170-5180, 2010.

[79] A. J. Nauta, B. Bottazzi, A. Mantovani et al., "Biochemical and functional characterization of the interaction between pentraxin 3 and C1q," European Journal of Immunology, vol. 33, no. 2, pp. 465-473, 2003.

[80] L. Deban, R. Castro Russo, M. Sironi et al., "Regulation of leukocyte recruitment by the long pentraxin PTX3," Nature Immunology, vol. 11, no. 4, pp. 328-334, 2010.

[81] L. Deban, H. Jarva, M. J. Lehtinen et al., "Binding of the long pentraxin PTX3 to factor $\mathrm{H}$ : interacting domains and function in the regulation of complement activation," Journal of Immunology, vol. 181, no. 12, pp. 8433-8440, 2008.

[82] A. Inforzato, V. Rivieccio, A. P. Morreale et al., "Structural characterization of PTX3 disulfide bond network and its multimeric status in cumulus matrix organization," Journal of Biological Chemistry, vol. 283, no. 15, pp. 10147-10161, 2008.

[83] A. Inforzato, C. Baldock, T. A. Jowitt et al., "The angiogenic inhibitor long pentraxin PTX3 forms an asymmetric octamer with two binding sites for FGF2," Journal of Biological Chemistry, vol. 285, no. 23, pp. 17681-17692, 2010.

[84] Y. J. Ma, A. Doni, T. Hummelshoj et al., "Synergy between ficolin-2 and PTX3 boost innate immune recognition and complement deposition," The Journal of Biological Chemistry, vol. 284, no. 41, pp. 28263-28275, 2009.

[85] J. Zhang, J. Koh, J. Lu et al., "Local inflammation induces complement crosstalk which amplifies the antimicrobial response," PLoS Pathogens, vol. 5, no. 1, Article ID e1000282, 2009.

[86] Y. J. Ma, A. Doni, M. O. Skjoedt et al., "Heterocomplexes of mannose-binding lectin and the pentraxins PTX3 or SAP trigger cross-activation of the complement system," The Journal of Biological Chemistry, vol. 286, no. 5, pp. 34053417, 2011.

[87] C. Garianda, E. Hirsch, S. Bozza et al., "Non-redundant role of the long pentraxin PTX3 in anti-fungal innate immune response," Nature, vol. 420, no. 6912, pp. 182-186, 2002.

[88] S. N. Diniz, R. Nomizo, P. S. Cisalpino et al., "PTX3 function as an opsonin for the dectin-1-dependent internalization of zymosan by macrophages," Journal of Leukocyte Biology, vol. 75, no. 4, pp. 649-656, 2004.

[89] S. Bozza, F. Bistoni, R. Gaziano et al., "Pentraxin 3 protects from MCMV infection and reactivation through TLR sensing pathways leading to IRF3 activation," Blood, vol. 108, no. 10, pp. 3387-3396, 2006.

[90] R. Gaziano, S. Bozza, S. Bellocchio et al., "Anti-Aspergillus fumigatus efficacy of pentraxin 3 alone and in combination with antifungals," Antimicrobial Agents and Chemotherapy, vol. 48, no. 11, pp. 4414-4421, 2004.

[91] P. C. Reading, S. Bozza, B. Gilbertson et al., "Antiviral activity of the long chain pentraxin PTX3 against influenza viruses," Journal of Immunology, vol. 180, no. 5, pp. 3391-3398, 2008.

[92] P. Jeannin, B. Bottazzi, M. Sironi et al., "Complexity and complementarity of outer membrane protein A recognition by cellular and humoral innate immunity receptors," Immunity, vol. 22, no. 5, pp. 551-560, 2005.

[93] L. M. Stuart, K. Takahashi, L. Shi, J. Savill, and R. A. Ezekowitz, "Mannose-binding lectin-deficient mice display defective apoptotic cell clearance but no autoimmune phenotype," Journal of Immunology, vol. 174, no. 6, pp. 3220-3226, 2005.

[94] A. Cotena, V. Maina, M. Sironi et al., "Complement dependent amplification of the innate response to a cognate microbial ligand by the long pentraxin PTX3," Journal of Immunology, vol. 179, no. 9, pp. 6311-6317, 2007.

[95] C. D’Angelo, A. De Luca, T. Zelante et al., "Exogenous pentraxin 3 restores antifungal resistance and restrains inflammation in murine chronic granulomatous disease," Journal of Immunology, vol. 183, no. 7, pp. 4609-4618, 2009.

[96] A. C. Soares, D. G. Souza, V. Pinho et al., "Dual function of the long pentraxin PTX3 in resistance against pulmonary infection with Klebsiella pneumoniae in transgenic mice," Microbes and Infection, vol. 8, no. 5, pp. 1321-1329, 2006.

[97] E. R. Job, Y. M. Deng, M. D. Tate et al., "Pandemic H1N1 influenza A viruses are resistant to the antiviral activities of innate immune proteins of the collectin and pentraxin superfamilies," Journal of Immunology, vol. 185, pp. 42844291, 2010.

[98] J. Jongstra-Bilen, R. Harrison, and S. Grinstein, "Fcgammareceptors induce Mac-1 (CD11b/CD18) mobilization and accumulation in the phagocytic cup for optimal phagocytosis," Journal of Biological Chemistry, vol. 278, no. 46, pp. 45720-45729, 2003.

[99] R. Olesen, C. Wejse, D. R. Velez et al., "DC-SIGN (CD209), pentraxin 3 and vitamin $\mathrm{D}$ receptor gene variants associate with pulmonary tuberculosis risk in West Africans," Genes and Immunity, vol. 8, no. 6, pp. 456-467, 2007.

[100] M. Chiarini, C. Sabelli, P. Melotti et al., "PTX3 genetic variations affect the risk of Pseudomonas aeruginosa airway colonization in cystic fibrosis patients," Genes and Immunity, vol. 11, no. 8, pp. 665-670, 2010.

[101] G. D. Norata, C. Garlanda, and A. L. Catapano, "The long pentraxin PTX3: a modulator of the immunoinflammatory response in atherosclerosis and cardiovascular diseases," Trends in Cardiovascular Medicine, vol. 20, no. 2, pp. 35-40, 2010.

[102] B. Han, J. J. Haitsma, Y. Zhang et al., "Long pentraxin PTX3 deficiency worsens LPS-induced acute lung injury," Intensive Care Medicine, vol. 37, no. 2, pp. 334-342, 2011.

[103] P. Jeannin, S. Jaillon, and Y. Delneste, "Pattern recognition receptors in the immune response against dying cells," Current Opinion in Immunology, vol. 20, no. 5, pp. 530-537, 2008. 
[104] A. P. van Rossum, F. Fazzini, P. C. Limburg et al., "The prototypic tissue pentraxin PTX3, in contrast to the short pentraxin serum amyloid $\mathrm{P}$, inhibits phagocytosis of late apoptotic neutrophils by macrophages," Arthritis and Rheumatism, vol. 50, no. 8, pp. 2667-2674, 2004.

[105] D. Gershov, S. Kim, N. Brot, and K. B. Elkon, "C-reactive protein binds to apoptotic cells, protects the cells from assembly of the terminal complement components, and sustains an antiinflammatory innate immune response: implications for systemic autoimmunity," Journal of Experimental Medicine, vol. 192, no. 9, pp. 1353-1364, 2000.

[106] P. Rovere, G. Peri, F. Fazzini et al., "The long pentraxin PTX3 binds to apoptotic cells and regulates their clearance by antigen-presenting dendritic cells," Blood, vol. 96, pp. 43004306, 2000.

[107] P. Baruah, I. E. Dumitriu, G. Peri et al., "The tissue pentraxin PTX3 limits C1q-mediated complement activation and phagocytosis of apoptotic cells by dendritic cells," Journal of Leukocyte Biology, vol. 80, no. 1, pp. 87-95, 2006.

[108] P. Baruah, A. Propato, I. E. Dumitriu et al., "The pattern recognition receptor PTX3 is recruited at the synapse between dying and dendritic cells, and edits the crosspresentation of self, viral, and tumor antigens," Blood, vol. 107, pp. 151-158, 2006.

[109] L. A. Trouw, A. A. Bengtsson, K. A. Gelderman, B. Dahlbäck, G. Sturfelt, and A. M. Blom, "C4b-binding protein and factor $\mathrm{H}$ compensate for the loss of membrane-bound complement inhibitors to protect apoptotic cells against excessive complement attack," Journal of Biological Chemistry, vol. 282, no. 39, pp. 28540-28548, 2007.

[110] S. Jaillon, P. Jeannin, Y. Hamon et al., "Endogenous PTX3 translocates at the membrane of late apoptotic human neutrophils and is involved in their engulfment by macrophages," Cell Death and Differentiation, vol. 16, pp. 465-474, 2009.

[111] I. K. Poon, M. D. Hulett, and C. R. Parish, "Molecular mechanisms of late apoptotic/necrotic cell clearance," Cell Death and Differentiation, vol. 17, no. 3, pp. 381-397, 2010.

[112] D. L. Russell and A. Salustri, "Extracellular matrix of the cumulus-oocyte complex," Seminars in Reproductive Medicine, vol. 24, no. 4, pp. 217-227, 2006.

[113] S. Varani, J. A. Elvin, C. Yan et al., "Knockout of pentraxin 3, a downstream target of growth differentiation factor-9, causes female subfertility," Molecular Endocrinology, vol. 16, no. 6, pp. 1154-1167, 2002.

[114] A. Salustri, C. Garlanda, E. Hirsch et al., "PTX3 plays a key role in the organization of the cumulus oophorus extracellular matrix and in in vivo fertilization," Development, vol. 131, pp. 1577-1586, 2004.

[115] L. Zhuo, M. Yoneda, M. Zhao et al., "Defect in SHAPhyaluronan complex causes severe female infertility. A study by inactivation of the bikunin gene in mice," Journal of Biological Chemistry, vol. 276, no. 11, pp. 7693-7696, 2001.

[116] C. Fülöp, S. Szántó, D. Mukhopadhyay et al., "Impaired cumulus mucification and female sterility in tumor necrosis factor-induced protein-6 deficient mice," Development, vol. 130, no. 10, pp. 2253-2261, 2003.

[117] M. S. Rugg, A. C. Willis, D. Mukhopadhyay et al., "Characterization of complexes formed between TSG-6 and inter-alphainhibitor that act as intermediates in the covalent transfer of heavy chains onto hyaluronan," The Journal of Biological Chemistry, vol. 280, pp. 25674-25686, 2005.

[118] A. J. Day and C. A. de la Motte, "Hyaluronan crosslinking: a protective mechanism in inflammation?" Trends in Immunology, vol. 26, no. 12, pp. 637-643, 2005.
[119] J. Folkman, "Angiogenesis in cancer, vascular, rheumatoid and other disease," Nature Medicine, vol. 1, no. 1, pp. 27-31, 1995.

[120] M. Presta, P. Dell'Era, S. Mitola, E. Moroni, R. Ronca, and M. Rusnati, "Fibroblast growth factor/fibroblast growth factor receptor system in angiogenesis," Cytokine and Growth Factor Reviews, vol. 16, no. 2, pp. 159-178, 2005.

[121] M. Rusnati, M. Camozzi, E. Moroni et al., "Selective recognition of fibroblast growth factor-2 by the long pentraxin PTX3 inhibits angiogenesis," Blood, vol. 104, no. 1, pp. 92-99, 2004.

[122] M. Camozzi, S. Zacchigna, M. Rusnati et al., "Pentraxin 3 inhibits fibroblast growth factor 2-dependent activation of smooth muscle cells in vitro and neointima formation in vivo," Arteriosclerosis, Thrombosis, and Vascular Biology, vol. 25, no. 9, pp. 1837-1842, 2005.

[123] R. S. Schwartz and T. D. Henry, "Pathophysiology of coronary artery restenosis," Reviews in Cardiovascular Medicine, vol. 3, supplement 5, pp. S4-S9, 2002.

[124] D. Leali, P. Alessi, D. Coltrini, M. Rusnati, L. Zetta, and M. Presta, "Fibroblast growth factor-2 antagonist and antiangiogenic activity of long-pentraxin 3-derived synthetic peptides," Current Pharmaceutical Design, vol. 15, no. 30, pp. 3577-3589, 2009.

[125] P. Alessi, D. Leali, M. Camozzi, A. Cantelmo, A. Albini, and M. Presta, "Anti-FGF2 approaches as a strategy to compensate resistance to anti-VEGF therapy: long-pentraxin 3 as a novel antiangiogenic FGF2-antagonist," European Cytokine Network, vol. 20, no. 4, pp. 225-234, 2009.

[126] F. Willeke, A. Assad, P. Findeisen et al., "Overexpression of a member of the pentraxin family (PTX3) in human soft tissue liposarcoma," European Journal of Cancer, vol. 42, no. 15, pp. 2639-2646, 2006.

[127] G. Germano, R. Frapolli, M. Simone et al., "Antitumor and anti-inflammatory effects of trabectedin on human myxoid liposarcoma cells," Cancer Research, vol. 70, no. 6, pp. 22352244, 2010.

[128] E. P. Diamandis, L. Goodglick, C. Planque, and M. D. Thornquist, "Pentraxin-3 is a novel biomarker of lung carcinoma," Clinical Cancer Research, vol. 17, no. 8, pp. 23952399, 2011.

[129] C. Planque, V. Kulasingam, C. R. Smith, K. Reckamp, L. Goodglick, and E. P. Diamandis, "Identification of five candidate lung cancer biomarkers by proteomics analysis of conditioned media of four lung cancer cell lines," Molecular and Cellular Proteomics, vol. 8, no. 12, pp. 2746-2758, 2009.

[130] L. Ravenna, P. Sale, M. Di Vito et al., "Up-regulation of the inflammatory-reparative phenotype in human prostate carcinoma," The Prostate, vol. 69, no. 11, pp. 1245-1255, 2009.

[131] A. Mantovani, C. Garlanda, A. Doni, and B. Bottazzi, "Pentraxins in innate immunity: from C-reactive protein to the long pentraxin PTX3," Journal of Clinical Immunology, vol. 28, no. 1, pp. 1-13, 2008.

[132] A. Azzurri, O. Y. Sow, A. Amedei et al., "IFN-gammainducible protein 10 and pentraxin 3 plasma levels are tools for monitoring inflammation and disease activity in Mycobacterium tuberculosis infection," Microbes and Infection, vol. 7, no. 1, pp. 1-8, 2005.

[133] A. T. Mairuhu, G. Peri, T. E. Setiati et al., "Elevated plasma levels of the long pentraxin, pentraxin 3, in severe dengue virus infections," Journal of Medical Virology, vol. 76, no. 4, pp. 547-552, 2005.

[134] T. Mauri, G. Bellani, N. Patroniti et al., "Persisting high levels of plasma pentraxin 3 over the first days after severe 
sepsis and septic shock onset are associated with mortality," Intensive Care Medicine, vol. 36, no. 4, pp. 621-629, 2010.

[135] T. Sprong, G. Peri, C. Neeleman et al., "Pentraxin 3 and Creactive protein in severe meningococcal disease," Shock, vol. 31, no. 1, pp. 28-32, 2009.

[136] I. Cetin, V. Cozzi, F. Pasqualini et al., "Elevated maternal levels of the long pentraxin 3 (PTX3) in preeclampsia and intrauterine growth restriction," American Journal of Obstetrics and Gynecology, vol. 194, no. 5, pp. 1347-1353, 2006.

[137] P. Rovere-Querini, S. Antonacci, G. Dell'Antonio et al., "Plasma and tissue expression of the long pentraxin 3 during normal pregnancy and preeclampsia," Obstetrics and Gynecology, vol. 108, no. 1, pp. 148-155, 2006.

[138] F. Assi, R. Fruscio, C. Bonardi et al., "Pentraxin 3 in plasma and vaginal fluid in women with preterm delivery," British Journal of Obstetrics and Gynaecology, vol. 114, no. 2, pp. 143147, 2007.

[139] L. Cruciani, R. Romero, E. Vaisbuch et al., "Pentraxin 3 in maternal circulation: an association with preterm labor and preterm PROM, but not with intra-amniotic infection/inflammation," Journal of Maternal-Fetal and Neonatal Medicine, vol. 23, pp. 1097-1105, 2010.

[140] M. Kacerovsky, J. Tosner, M. Drahosova, H. Hornychova, and C. Andrys, "Pentraxin 3 in amniotic fluid as a marker of intra-amniotic inflammation in women with preterm premature rupture of membranes," International Journal of Gynecology \& Obstetrics, vol. 108, pp. 203-206, 2010.

[141] L. Cruciani, R. Romero, E. Vaisbuch et al., "Pentraxin 3 in amniotic fluid: a novel association with intra-amniotic infection and inflammation," Journal of Perinatal Medicine, vol. 38, no. 2, pp. 161-171, 2010. 


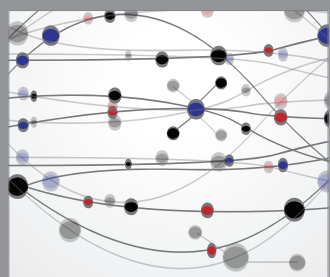

The Scientific World Journal
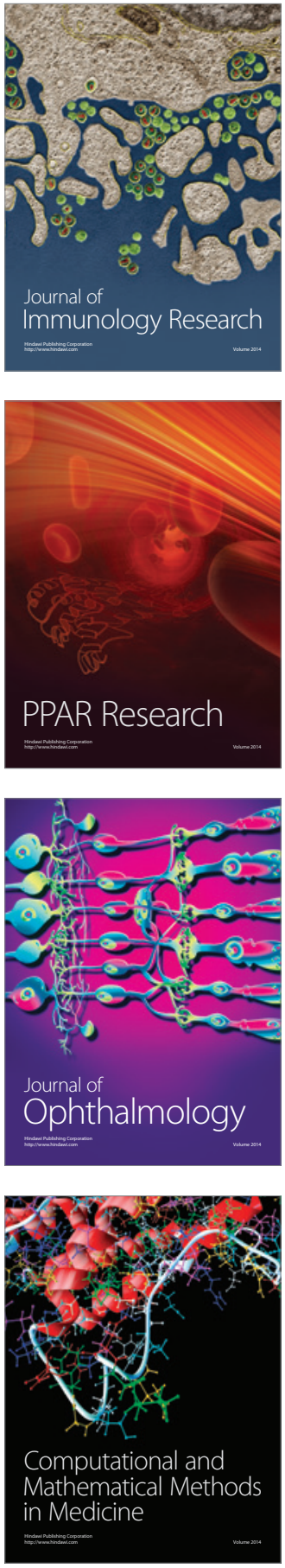

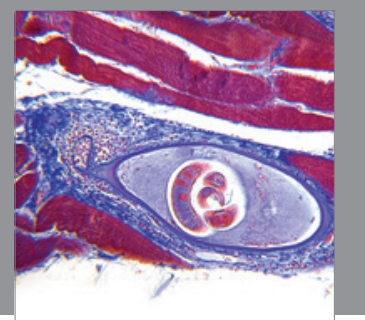

Gastroenterology

Research and Practice
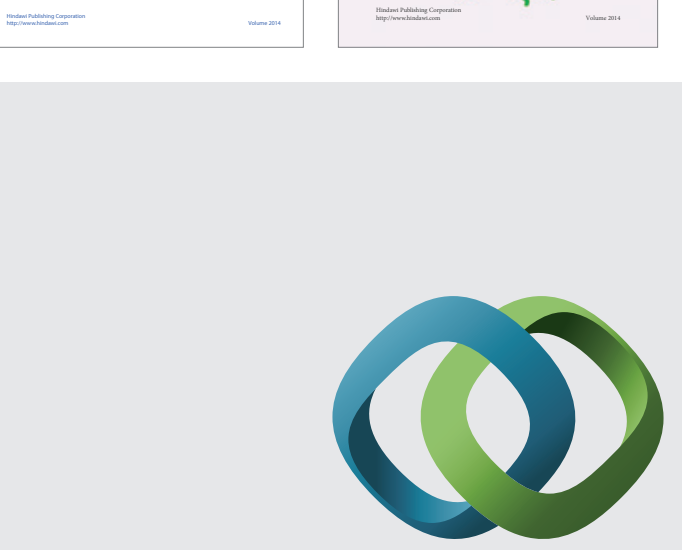

\section{Hindawi}

Submit your manuscripts at

http://www.hindawi.com
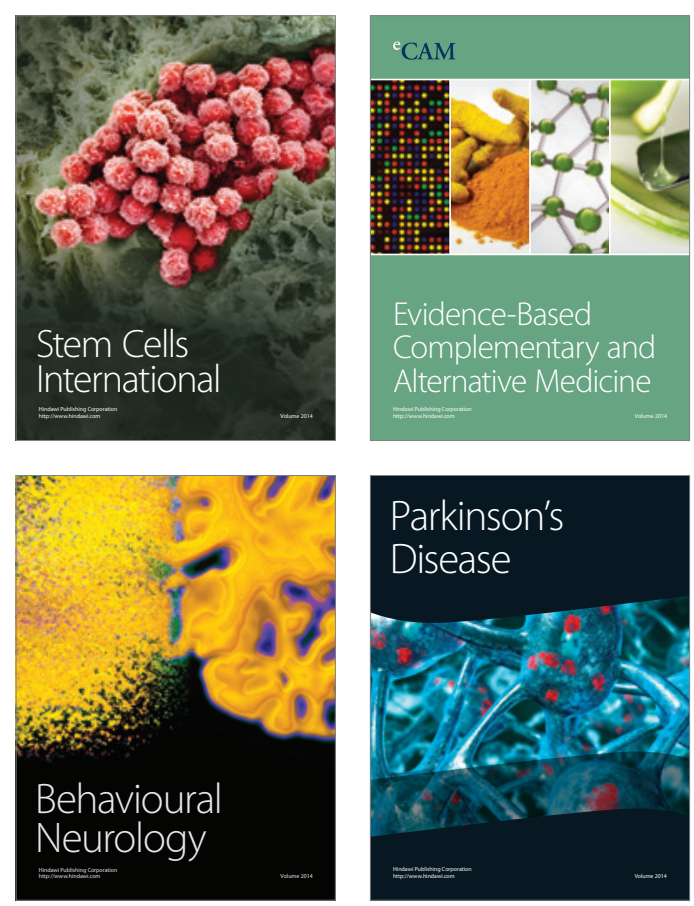

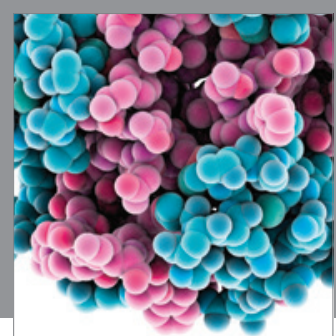

Journal of
Diabetes Research

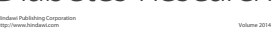

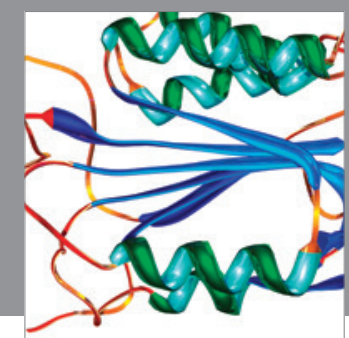

Disease Markers
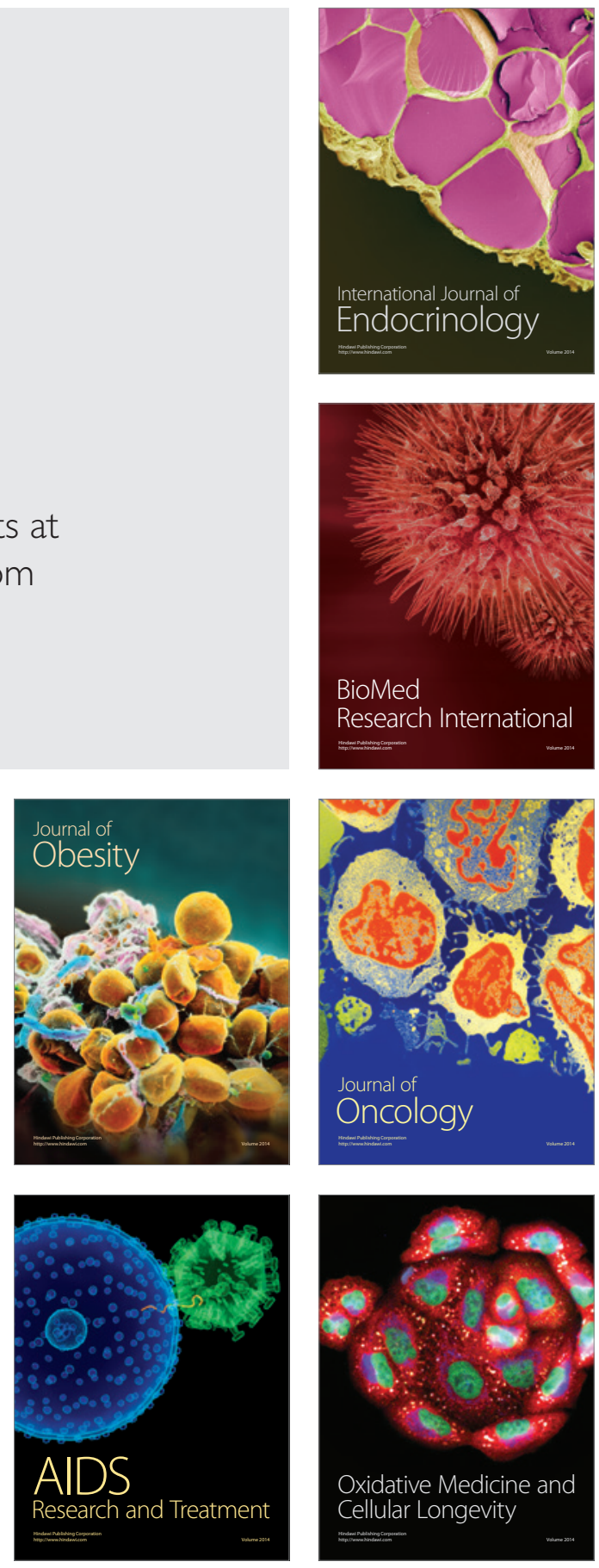